\title{
Presença feminina no estudo e no trabalho da ciência na Unicamp*
}

\author{
Elza da Costa Cruz Vasconcellos** \\ Sandra Negraes Brisolla***
}

\begin{abstract}
Resumo
O objetivo deste trabalho é contribuir para a superação de obstáculos à elevação da produtividade científica e melhoria das condições de trabalho e da cooperação entre cientistas homens $e$ mulheres na produção de conhecimento. Os resultados parciais do estudo de caso na Universidade Estadual de Campinas (Unicamp) apontam para a inexistência de diferenças reais por sexo na capacidade de aprendizado e na dedicação dos alunos nas carreiras que se consideram "masculinas", que incluem as ciências exatas e tecnológicas ou engenharias. Pelo contrário, na grande maioria dos cursos da Unicamp - universidade que se diferencia das demais pelo predomínio dessas carreiras - por razões múltiplas, que se trata de identificar, as alunas têm apresentado melhores coeficientes de rendimento que seus colegas nos mesmos cursos. Por esse motivo, o pouco interesse das vestibulandas por cursos dessa natureza só é explicável por hábitos culturais e preconceitos que se enraizaram na forma diferenciada com que se criam as meninas e os meninos.
\end{abstract}

Palavras-chave: Ciências Exatas, Engenharia, Desigualdade por Sexo no Trabalho.

\footnotetext{
* Recebido para publicação em março de 2008, aceito em setembro de 2008. Este trabalho é um dos principais resultados do projeto "A mulher e seu lugar na comunidade científica", coordenado pelas autoras e financiado pelo CNPq

** Professora associada do Instituto de Física Gleb Wataghin, Unicamp. elza@ifi.unicamp.br

*** Professora associada do Instituto de Geociências, Unicamp. brisolla@ige.unicamp.br
}

cadernos pagu (32), janeiro-junho de 2009:215-265. 
Presença feminina no estudo e no trabalho da ciência na Unicamp

\title{
Women as Students and Scientists at Unicamp
}

\begin{abstract}
The main objective of this work is to help overcome obstacles which prevent a more efficient scientific production and improvement of the work conditions and cooperation among men and women scientists in knowledge creation. The preliminary results of the State University of Campinas (Unicamp) case study indicate no real differences by sex concerning the students learning abilities and academic commitment in careers considered to be male dominated - the hard sciences (mathematics, physics, chemistry, biology, engineering, etc). In fact, at Unicamp where differently from other universities there is a predominance of hard science courses, female students have outperformed their male counterparts in the majority of Unicamp's courses. Thus, the little interest shown by female candidates in the choice of hard science careers when applying for the university's entrance exam, is certainly biased by cultural habits and prejudices intrinsic to the different ways of raising girls and boys.
\end{abstract}

Key Words: Exact Sciences, Engineering, Sex Inequalities at Work. 
Elza Vasconcellos e Sandra Brisolla

\section{Introdução}

Tratando-se de uma atividade que se executa principalmente através do exercício do raciocínio, pela aplicação de conhecimentos e utilização de metodologias aprendidas no cotidiano da pesquisa, a produção acadêmica se organiza através de uma hierarquia baseada no mérito científico, ou seja, é meritocrática e não burocrática. Essa característica permite supor que a progressão na carreira de cientistas dedicados à pesquisa $e$ à docência não seria contaminada (ou o seria em menor medida) pelos preconceitos prevalecentes na sociedade que estão na base da discriminação por gênero. ${ }^{1}$ No entanto, tal hipótese significaria supor que os cientistas e pesquisadores em geral estariam acima das determinações sociais que são responsáveis pelos atos $e$ pensamentos discriminatórios, muitos deles sendo parte do subconsciente dos seres humanos, homens e mulheres. ${ }^{2}$

Há uma dupla forma de inserção desvantajosa das mulheres no mercado de trabalho: por um lado, são reservadas a elas funções menos complexas e menos valorizadas de sua área de atuação. Por outro, a organização social cria obstáculos, alguns reais, outros ideológicos, para a ascensão na carreira e ocupação de postos hierarquizados.

1 O conceito de gênero é mais amplo do que o de sexo, incluindo condicionamentos sociais e culturais responsáveis pela diferenciação de oportunidades, de funções e de capacidades historicamente desenvolvidas entre os sexos. Este trabalho não trata particularmente dessa questão, que tem merecido ampla reflexão na literatura feminista. Ver, por exemplo, FaustoSterling (2001/02).

2 Destaque-se que a mulher é também responsável por sua situação subordinada, quando reproduz essa atitude servil ou de dependência, não apenas assumindo funções não hierarquizadas, como aceitando esses papéis secundários no ambiente do trabalho. Também ao nível doméstico, é grande a parcela de responsabilidade das mulheres na socialização dos filhos e filhas, reproduzindo os estigmas sexistas e perpetuando a subordinação. 
Presença feminina no estudo e no trabalho da ciência na Unicamp

Este artigo compreende uma radiografia da situação atual das mulheres na ciência através de um estudo de caso dos alunos e docentes da Universidade Estadual de Campinas (Unicamp), cuja escolha se justifica pela predominância de cursos e docentes das carreiras exatas, tecnológicas e biológicas, tidas como predominantemente masculinas. Constitui um caso único no país de universidade que tem dois terços dos cursos, dos alunos e dos docentes em carreiras das áreas exatas, tecnológicas e biológicas. A Unicamp iniciou sua institucionalização com presença ainda mais expressiva de professores do sexo masculino nos cargos de direção ${ }^{3}$, e essa situação prevalece há muito tempo, embora esteja sendo suavizada na atualidade.

O estudo da Unicamp tem especial interesse em razão da imagem de universidade democrática. A análise explora, inicialmente, a presença das mulheres no corpo discente e seu desempenho acadêmico.

Este trabalho contém resultados parciais dos alunos e um comentário geral com alguns dados preliminares dos docentes. Assim, o projeto trata também de examinar a evolução da situação das mulheres na ciência, não apenas pela progressiva entrada de alunas nos cursos considerados masculinos, como pela ascensão na carreira docente que, a médio prazo, vai se refletir na composição por gênero do corpo acadêmico. A proposta inclui o exame das condições que diferenciam o desempenho acadêmico dos alunos por sexo, em contexto de maior igualdade de oportunidades, daquelas que dividem a progressão na carreira docente ou científica, cujos interesses mais solidamente instituídos

\footnotetext{
3 Esse fenômeno é conhecido na literatura sobre gênero como o "teto de vidro", em alusão ao fato de ser um mecanismo discriminatório quase invisível. Do inglês, em referência ao mesmo fenômeno nos Estados Unidos, Glass Ceiling, constitui uma alusão ao fato de que a maior participação feminina no mercado de trabalho não se refletiu de forma significativa em maior presença de mulheres em postos mais valorizados do mercado de trabalho. Cf. Davidson \& Cooper (1992), Morrison, \& Velsor (1992) e Tabak (2002). Sobre o mesmo fenômeno no mercado de trabalho em geral, ver Maruani \& Hirata (2003).
} 
resistem mais firmemente à alteração dos hábitos de produção de ciência. Essa última tem rituais e formas de organização que se enraízam claramente nos esquemas de condução dos destinos das universidades e, fora delas, nas agências de fomento à pesquisa $e$ em outras esferas do poder científico - academias e sociedades científicas - tradicionalmente dominadas por homens.

A superação dessa situação discriminatória beneficia não apenas as mulheres subordinadas a essa dominação, como os homens que, ao ver as colegas como parceiras, passam a desfrutar de uma relação mais frutífera na produção de conhecimento. Mas beneficia principalmente a ciência, com o aumento do número $e$ melhora da qualidade de cientistas que antes tinham menor oportunidade de revelar sua potencialidade. Assim, um projeto dessa natureza tem toda possibilidade de resultar em um aumento da produtividade científica e em uma melhora significativa do ambiente de trabalho nos laboratórios e nos âmbitos em que a ciência é produzida, discutida, legitimada e difundida em suas múltiplas e complexas instituições.

Se não há nenhum fator inerente ao funcionamento do capitalismo que justifique a discriminação da mulher no mercado de trabalho (tampouco na produção científica), pode-se supor que não há motivos de peso para que essa situação se mantenha indefinidamente (Brisolla, 1983:36). Como argumentava Madeleine Guilbert, já em meados dos anos 1960, pensar na permanência da distinção entre trabalho masculino e feminino equivale a supor que transformações tão radicais no domínio da técnica produzir-se-iam numa sociedade para a qual todos os valores permaneceriam imutáveis, em particular aqueles que decidem da participação ou não das mulheres na vida profissional (Guilbert, 1966:227).

\section{Mais alunas em cursos "masculinos"}

Este trabalho mostra resultados parciais de uma pesquisa em andamento que trata da evolução das relações de sexo, através do estudo de estatísticas sobre os alunos, além de 
Presença feminina no estudo e no trabalho da ciência na Unicamp

informações administrativas e entrevistas com docentes na Universidade Estadual de Campinas (Unicamp).

A primeira parte trata da composição do alunado por sexo nas carreiras oferecidas pela universidade. De 1970 a 2005, o número de alunos ingressantes na Unicamp cresceu oito vezes, sendo o número de estudantes do sexo masculino, em 2005, seis vezes maior que em 1970, enquanto o número de alunas multiplicou-se por mais de 14 vezes. Assim, se em 1970 apenas um quarto dos alunos que começavam a cursar a universidade eram mulheres (24,7\%), em 2005 elas eram mais de 40\% (43,5\%) (tabela 1).

Tabela 1

Alunos ingressantes na Unicamp por sexo 1970 até a atualidade

\begin{tabular}{cccccccc}
\hline \multicolumn{7}{c}{ Índice $1970=100$} \\
$\begin{array}{c}\text { Ano de } \\
\text { Ingresso }\end{array}$ & $\begin{array}{c}\text { Número } \\
\text { de Cursos }\end{array}$ & $\begin{array}{c}\text { Alunos } \\
\text { Ingressantes }\end{array}$ & $\begin{array}{c}\text { Masculino } \\
\%\end{array}$ & $\begin{array}{c}\text { Feminino } \\
\%\end{array}$ & $\begin{array}{c}\text { Total } \\
\text { Alunos }\end{array}$ & Masc & Fem \\
\hline 1970 & 11 & 470 & 75,3 & 24,7 & 100 & 100 & 100 \\
1980 & 22 & 1.395 & 61,4 & 38,6 & 297 & 242 & 464 \\
1990 & 31 & 1.466 & 55,3 & 44,7 & 312 & 229 & 564 \\
2000 & 50 & 2.484 & 56,5 & 42,7 & 529 & 397 & 914 \\
2005 & 58 & 3.851 & 56,6 & 43,5 & 819 & 616 & 1.440 \\
\hline
\end{tabular}

Nas áreas de exatas e tecnológicas, consideradas de perfil masculino, essa evolução indica um acréscimo no ingresso de mulheres. Ainda assim, essa informação deve ser relativizada, devido ao aumento de percentual ter-se dado, principalmente, nos primeiros vinte anos da universidade, quando estavam sendo implantadas as áreas de ciências humanas $e$ artes $e$ a área de ciências biológicas estava crescendo em ritmo relativamente maior que as demais. Mesmo com a aceleração recente do acréscimo no número de vagas na Unicamp, a composição por sexo não se modificou substancialmente, pois continuaram a ser privilegiadas 
as áreas exatas e tecnológicas (engenharias), que caracterizam sua vocação desde o início de suas atividades. ${ }^{4}$

\section{Comportamento diferenciado por gênero}

O conjunto de dados analisado, fornecido pela COMVEST ${ }^{5}$, é composto de informações de 6701 alunos que ingressaram na universidade entre 1994 e 1997 (excluídos os alunos dos colégios técnicos).

As informações se referem às respostas dos estudantes ao questionário sócio-cultural aplicado no momento de inscrição no vestibular, $e$ incluem dados como: nota final do vestibular padronizada, coeficiente de rendimento (CR) final do aluno, curso, área e período em que estuda ou estudou na graduação, situação (ativo, formado ou jubilado). As informações foram atualizadas até o primeiro semestre de 2003.

A escolha dessa amostra deveu-se a que, nesse período, grande parte desses alunos já havia deixado a universidade (formado ou jubilado); apenas 2,25\% (151 alunos) estavam ainda ativos. A percentagem média de alunos formados e jubilados foi de $72,18 \%$ e $25,56 \%$, respectivamente.

\footnotetext{
4 As mulheres são, no entanto, mais numerosas no ensino superior privado no país, o que reflete em parte a composição desse sistema por áreas, pois nele prevalecem os cursos de ciências humanas e sociais, cujos custos bem menores do que os das "hard sciences" (exatas, biológicas e engenharias) oferecidos principalmente pelas universidades públicas.

5 Comissão do Vestibular da Unicamp que organiza o exame de ingresso na universidade e aplica um questionário aos alunos que concorrem às vagas. Aqui foram utilizados os questionários dos alunos aprovados de uma amostra que foi trabalhada pelos pesquisadores da Comvest, com a finalidade de introduzir $e$ testar critérios de favorecimento com créditos a candidatos ao vestibular que fizeram o curso básico em escola pública e também aos que se declaram negros ou indígenas. A equipe de pesquisa agradece a colaboração de Renato $\mathrm{H}$. L Pedrosa, Mauricio Kleinke, J. Norberto W. Dachs, Rafael P. Maia, Cibele Y. Andrade, pelo fornecimento de informações que permitiram a construção dessas tabelas e as reflexões a elas relacionadas.
} 
Presença feminina no estudo e no trabalho da ciência na Unicamp

Dos 6701 alunos, 4051 (60,5\%) são do sexo masculino, 2590 $(38,7 \%)$ do sexo feminino e para 60 alunos falta esta informação $(0,8 \%)$. Nessa amostra, os alunos das áreas de ciências humanas e artes representavam apenas um quarto do total (tabela 2).

Tabela 2

Distribuição da amostra por áreas e por sexo.

\begin{tabular}{lcccccc}
\hline \multirow{2}{*}{\multicolumn{1}{c}{ Área }} & \multicolumn{3}{c}{ Sexo } & \multicolumn{2}{c}{ Total } \\
\cline { 2 - 5 } & \multicolumn{2}{c}{ Masculino } & \multicolumn{2}{c}{ Feminino } & & \\
\cline { 2 - 6 } & $\mathrm{n}$ & $\%$ & $\mathrm{n}$ & $\%$ & $\mathrm{n}$ & $\%$ \\
\hline Exatas & 856 & 73,6 & 307 & 26,4 & 1163 & 17,5 \\
Engenharias & 1917 & 76,2 & 598 & 23,8 & 2515 & 37,9 \\
Bio\&Saúde & 575 & 43,1 & 760 & 56,9 & 1335 & 20,1 \\
Humanas & 512 & 42,0 & 708 & 58,0 & 1220 & 18,4 \\
Artes & 191 & 46,8 & 217 & 53,2 & 408 & 6,1 \\
\hline Total & 4051 & 61,0 & 2590 & 39,0 & 6641 & 100,0 \\
\hline
\end{tabular}

A distribuição da amostra segundo áreas do conhecimento $e$ sexo revela que, assim como no caso dos ingressantes anuais da universidade, nas áreas de ciências exatas e engenharias há uma forte predominância de estudantes do sexo masculino $(73,6 \%$ e $76,2 \%$ respectivamente). Nas demais áreas, a percentagem de mulheres é um pouco maior, comparada à dos homens, variando entre 53,2\% (artes) e 58\% (humanas) (tabela 2).

Os sete cursos mais concorridos em 1997 (com maior relação de candidatos/vaga na primeira fase) foram: medicina, odontologia, biologia diurno, ciência da computação, engenharia da computação, engenharia de alimentos e enfermagem. A distribuição dos estudantes por gênero em cada um desses cursos $^{6}$, e também para os cursos mais concorridos das áreas de humanas e artes (ciências econômicas diurno, história diurno e

6 Nessas sete carreiras, que não incluem ciências humanas ou artes, o percentual de mulheres é de $42,8 \%$. 
artes cênicas), refere-se a um total de 2150 alunos, que representam $32,1 \%$ da amostra, e são indicativos das grandes diferenças de participação de alunas no conjunto dos estudantes por carreira, que ainda subsistem (tabela 3).

Os cursos que apresentaram maiores disparidades foram: enfermagem (com 94\% de mulheres), engenharia da computação (com $89,4 \%$ de homens) e ciência da computação (87,6\% de homens). Na medicina, a predominância é de homens $(55,7 \%) e$ em odontologia, biologia diurno e engenharia de alimentos, as mulheres estão em maior proporção $(67,8 ; 63,5$ e 62,5 respectivamente) (tabela 3 ).

Tabela 3

Distribuição da amostra por sexo para os sete cursos mais concorridos e os cursos mais concorridos da área de humanas e da área de artes

\begin{tabular}{|c|c|c|c|c|c|c|}
\hline \multirow{3}{*}{$\begin{array}{l}\text { Cursos mais } \\
\text { concorridos }\end{array}$} & \multicolumn{4}{|c|}{ sexo } & \multirow{2}{*}{\multicolumn{2}{|c|}{ Total }} \\
\hline & \multicolumn{2}{|c|}{ masculino } & \multicolumn{2}{|c|}{ feminino } & & \\
\hline & $\mathrm{n}$ & $\%$ & $\mathrm{n}$ & $\%$ & $\mathrm{n}$ & $\%$ \\
\hline Medicina & 202 & 55,6 & 161 & 44,4 & 363 & 100,0 \\
\hline Odontologia & 103 & 32,2 & 217 & 67,8 & 320 & 100,0 \\
\hline Biologia D & 46 & 36,5 & 80 & 63,5 & 126 & 100,0 \\
\hline Ciência da Computação & 134 & 87,6 & 19 & 12,4 & 153 & 100,0 \\
\hline Eng. da Computação & 328 & 89,4 & 39 & 10,6 & 367 & 100,0 \\
\hline Eng. de Alimentos & 105 & 37,5 & 175 & 62,5 & 280 & 100,0 \\
\hline Enfermagem & 5 & 6,0 & 78 & 94,0 & 83 & 100,0 \\
\hline Ciências Econômicas D & 180 & 62,5 & 108 & 37,5 & 288 & 100,0 \\
\hline História D & 39 & 40,6 & 57 & 59,4 & 96 & 100,0 \\
\hline Artes Cênicas & 33 & 44,6 & 41 & 55,4 & 74 & 100,0 \\
\hline Total & 1.175 & 54,6 & 975 & 45,4 & 2.150 & 100,0 \\
\hline
\end{tabular}

A grande diversidade de interesses pelos cursos oferecidos pela universidade reforça nossa convicção de que a média de participação de mulheres nos cursos universitários é fortemente definida pela composição de carreiras e de vagas disponíveis em cada uma delas (tabela 3). A Unicamp abre cerca de 55\% das 
Presença feminina no estudo e no trabalho da ciência na Unicamp

vagas para alunos ingressantes nas duas grandes áreas onde predominam os homens (exatas e engenharias) (tabela 2).

\section{Desempenho no vestibular e no final do curso, por sexo}

\subsection{Os homens se saem melhor no exame vestibular}

A princípio, avaliamos a colocação inicial do aluno, obtida a partir da nota final do vestibular padronizada com relação aos cursos.

\section{Média geral:}

Amostra total:

O posto relativo inicial médio masculino ${ }^{7}$ é de 0,518 (erro padrão ${ }^{8}=0,0045$ ) e o feminino 0,502 (erro padrão $=0,0056$ ). Há diferença significativa entre os sexos com relação ao posto inicial médio. ${ }^{9}$ A colocação das mulheres no exame vestibular ficou em média $3,1 \%$ mais baixa que a colocação dos homens.

7 O "posto relativo" ou "colocação inicial relativa" é a posição do aluno (rank, posto) com relação à nota do exame vestibular dentro de uma mesma turma, padronizada (normalizada) pelo número de alunos da turma (turma se refere ao grupo de alunos de um mesmo curso e mesmo ano de ingresso). Em cada turma, o posto 1 foi dado ao aluno que tinha a menor nota no vestibular e o posto "n" ( $\mathrm{n}$ = número de alunos da turma) para o aluno de maior nota. Cada posto foi dividido por "n", gerando o posto relativo. Quanto menor o posto relativo (mais perto de zero), pior foi a colocação inicial do aluno, e quanto mais próximo de 1 , melhor foi a colocação do aluno. A média aritmética dos postos ocupados pelos alunos é então comparada com a dos postos ocupados pelas alunas para a amostra, por área e por curso. À maior média dos postos corresponde o melhor desempenho do grupo em questão (alunos ou alunas; estudantes das áreas exatas ou das ciências humanas; etc.).

8 O erro padrão é um valor que expressa a raiz quadrada da média dos desvios quadrados em torno da média, dividida pela raiz quadrada de n (número de alunos), o que significa que o posto relativo inicial médio masculino varia, em média, de 0,518 - 0,0045 até 0,518 + 0,0045, ou seja, de 0,5135 a 0,5225. No caso feminino, o posto inicial médio varia em média de 0,4964 a 0,5076.

9 Para verificar se a diferença é significativa ao nível de $5 \%$ foi aplicado o teste tStudent, o p-valor encontrado foi de 0,0334. O nível de significância (que no 
Amostra de formados:

Vamos contrastar com esses resultados aqueles que foram calculados tomando apenas o sub-conjunto de alunos formados, deixando de lado os jubilados e os que abandonaram o curso no período analisado. Aqui se incluem apenas os alunos ingressantes na Unicamp entre 1994 e 1997 e que se formaram até o $1^{\circ}$ semestre de 2003. Essa sub-amostra é composta por 4797 estudantes, sendo 2754 do sexo masculino $(57,4 \%)$ e 2043 do sexo feminino $(42,6 \%)$.

Assim como no caso da amostra total, os homens apresentaram maior posto inicial médio, ficando a colocação das mulheres, em média, com posto inicial $4 \%$ menor que dos homens. Essa diferença em favor dos homens pode ser atribuída ao fato de jubilados e os que abandonaram o curso serem mais numerosos entre os alunos do que entre suas colegas. $\mathrm{O}$ desempenho dos homens no vestibular, portanto, deveria ser, como foi, melhor em média que o do conjunto de alunos, afastando-se do das mulheres:

Posto Inicial Homens /Posto Inicial Mulheres $=0,525 / 0,504=1,042$ Ou seja, os homens tem posto inicial $\mathbf{4 , 2 \%}$ maior que as mulheres. Posto Inicial Mulheres/Posto Inicial Homens = 0,504/0,525 = 0, 96. Em outras palavras, as mulheres tem posto inicial $4 \%$ menor que os homens.

\section{Por grandes áreas:}

Amostra total:

Voltando à amostra total, ao classificar os alunos por grandes áreas, a diferença por sexo na amostra total não é significativa (tabela 4). Apenas na área de ciências humanas, a diferença é estatisticamente significativa ao nível de 5\% (p-valor =

caso é de $5 \%$ ) é a probabilidade de cometer o erro de tipo 1 , que consiste em rejeitar a hipótese nula quando ela é verdadeira (a hipótese nula é de que a diferença das médias dessas populações é igual a zero). Rejeitando a hipótese nula (por ser de apenas $5 \%$ a probabilidade do erro de tipo 1 ), infere-se que existe diferença significativa entre as médias populacionais dos gêneros, no caso. 
Presença feminina no estudo e no trabalho da ciência na Unicamp

0,0026). Nessa área, o posto inicial médio masculino é de 0,544 (erro padrão $=0,0129$ ) e o feminino 0,493 (erro padrão $=0,0106$ ). O posto inicial feminino nessa área é, portanto, 9,4\% menor que o posto inicial masculino ${ }^{10}$ (tabela 4 ).

Tabela 4

Média e erro padrão do posto inicial por grande área e sexo

\begin{tabular}{lcccc}
\hline \multirow{2}{*}{ Área } & \multicolumn{4}{c}{ Sexo } \\
\cline { 2 - 5 } & \multicolumn{2}{c}{ Masculino } & \multicolumn{2}{c}{ Feminino } \\
\cline { 2 - 5 } & média & erro padrão & média & erro padrão \\
\hline Exatas & 0,518 & 0,010 & 0,503 & 0,017 \\
Engenharias & 0,510 & 0,007 & 0,506 & 0,012 \\
Bio\&Saúde & 0,522 & 0,012 & 0,502 & 0,010 \\
Humanas & 0,544 & 0,013 & 0,493 & 0,011 \\
Artes & 0,517 & 0,021 & 0,522 & 0,020 \\
\hline
\end{tabular}

Amostra de formados:

Nota-se que, em geral, os homens formados apresentaram maior posto inicial médio. Entretanto, as diferenças só foram significativas ao nível de $5 \%$ na amostra total e nas ciências exatas (tabela 5). No conjunto dos formados, as mulheres apresentaram, em média, posto inicial 3,8\% menor que os homens. Nas ciências exatas a diferença foi de $13,7 \%$.

Tabela 5

Posto inicial médio por sexo e por área

\begin{tabular}{lcccc}
\hline \multirow{2}{*}{ Área } & \multicolumn{3}{c}{ Sexo } \\
\cline { 2 - 5 } & \multicolumn{2}{c}{ masculino } & \multicolumn{2}{c}{ feminino } \\
\cline { 2 - 5 } & média & erro padrão & média & erro padrão \\
\hline Bio\&Saúde & 0,509 & 0,014 & 0,492 & 0,011 \\
Exatas & 0,564 & 0,016 & 0,487 & 0,021 \\
Engenharia & 0,518 & 0,008 & 0,521 & 0,013 \\
Humanas & 0,536 & 0,016 & 0,501 & 0,012 \\
Artes & 0,529 & 0,023 & 0,533 & 0,023 \\
\hline Total & 0,525 & 0,006 & 0,504 & 0,006 \\
\hline
\end{tabular}

$\overline{10}$ Obtido assim: $(0,493 / 0,544)-1=-9,4 \%$. 
Em nenhum dos cursos com maior demanda (tabela 3) houve diferença significativa entre os sexos no desempenho médio inicial dos alunos, na amostra total ou naquela que só inclui os formados.

4.2. As mulheres se formam com melhores colocações em todas as áreas

O posto final é a colocação do aluno em sua turma, obtida a partir de seu coeficiente de rendimento $(\mathrm{CR})$ final. Contrário ao que ocorre no posto inicial, o posto final médio feminino é, na maioria das vezes, superior ao masculino (tabela 6). As diferenças só não foram estatisticamente significativas nas ciências exatas e nas artes.

\section{Amostra total:}

Média geral:

A avaliação da colocação final média ${ }^{11}$, obtida a partir do coeficiente de rendimento (CR) final do aluno com relação ao sexo, para o conjunto da amostra, revelou diferença significativa ao nível de $5 \% .{ }^{12} \mathrm{O}$ posto final médio dos homens é de 0,480 (e.p. $=0,0045$ ) e o das mulheres 0,564 (e.p. $=0,0054$ ). As mulheres apresentam posto final médio $17,4 \%$ maior que o dos homens $(0,5636 / 0,4800-1)$ (tabelas 6 e 7).

\footnotetext{
${ }^{11} \mathrm{~A}$ colocação final foi obtida a partir da posição do aluno com relação ao $\mathrm{CR}$ (coeficiente de rendimento) final em uma mesma turma, dividido (normalizado) pelo número de alunos da turma.

${ }^{12} \mathrm{O}$ p-valor encontrado ao aplicar o teste $\mathrm{t}$ foi $0,0000(\mathrm{t}=11,7201)$.
} 
Presença feminina no estudo e no trabalho da ciência na Unicamp

Tabela 6

Proporção do posto final médio feminino comparado ao posto final

\begin{tabular}{lccc}
\multicolumn{4}{c}{ médio masculino } \\
\hline Área & $(\mathrm{pff} / \mathrm{pfm}-1)^{*}$ & \multicolumn{2}{c}{$\begin{array}{c}\text { Intervalo de Confiança } \\
\text { no nível de } 95 \%\end{array}$} \\
\hline Exatas & $100 \%$ & 16,1 & 31,7 \\
Engenharias & 23,6 & 8,8 & 19,7 \\
Bio\&Saúde & 14,1 & 22,3 & 39,0 \\
Humanas & 30,4 & 8,5 & 23,6 \\
Artes & 15,8 & 2,4 & 27,4 \\
\hline *pff = posto final médio feminino; $\mathrm{pfm}=$ posto final médio masculino
\end{tabular}

A diferença do rendimento relativo médio entre os sexos é significativa ao nível de 5\% em todas as áreas. Em todas elas, as mulheres apresentam maior desempenho relativo médio, atingindo um posto final médio superior ao dos homens (tabela 7).

Os percentuais mostram que as mulheres passam de uma posição média relativa $3,1 \%$ inferior aos homens no vestibular, para $17,4 \%$ superior no final do curso. Na área de ciências humanas, superam uma posição inicial 9,4\% inferior para atingir uma posição final $15,8 \%$ acima dos homens. Na área de bio\&saúde, onde houve maior disparidade, as mulheres chegam a galgar $30,4 \%$ a mais em relação ao posto médio inicial. Em seguida, se vai tentar levantar algumas hipóteses sobre essa diferença de desempenho, cruzando essa variável com outras, como a diferença entre sexos no percentual de alunos que abandonam o curso ou são jubilados. Mais adiante também, se vai averiguar em que medida o fato de parte dos estudantes trabalharem no momento do vestibular pode influir em seu rendimento e, portanto, no posto final médio. 
Elza Vasconcellos e Sandra Brisolla

Tabela 7

Média e erro padrão do posto final por grande área e sexo

\begin{tabular}{lcccc}
\hline \multirow{2}{*}{ Área } & \multicolumn{3}{c}{ Sexo } \\
\cline { 2 - 5 } & \multicolumn{2}{c}{ Masculino } & \multicolumn{2}{c}{ Feminino } \\
\cline { 2 - 5 } & média & erro padrão & média & erro padrão \\
\hline Exatas & 0.486 & 0.010 & 0.601 & 0.015 \\
Engenharias & 0.492 & 0.007 & 0.562 & 0.012 \\
Bio\&Saúde & 0.436 & 0.012 & 0.568 & 0.010 \\
Humanas & 0.473 & 0.013 & 0.547 & 0.011 \\
Artes & 0.484 & 0.021 & 0.553 & 0.019 \\
Todas as áreas & 0,480 & 0,0045 & 0,564 & 0,0054 \\
\hline
\end{tabular}

Amostra só de formados:

Média Geral:

Posto Final Homens /Posto Final Mulheres = 0,578/0,633 =0,9131.

Ou seja, os homens têm posto final $(1-0,9131)=\mathbf{8 , 7 \%}$ menor que as mulheres.

Posto Final Mulheres/Posto Final Homens = 0,633/0,578 = 1,095.

Ou seja, as mulheres têm posto final $\mathbf{9 , 5 \%}$ maior que os homens.

Observe-se que a diferença do posto final entre os sexos é menor nessa sub-amostra $(17,4 \%$ na média da amostra total comparados com $9,5 \%$ de vantagem para as mulheres no posto final da amostra dos formados) (tabela 8). Conforme já foi argumentado, essa diferença é, provavelmente, devida à presença de jubilados e desistentes na amostra global, mais numerosa entre os homens que entre as mulheres.

Tabela 8 - Posto final médio por sexo e por área

\begin{tabular}{lcccc}
\hline \multirow{2}{*}{ Área } & \multicolumn{3}{c}{ Sexo } \\
\cline { 2 - 5 } & \multicolumn{2}{c}{ masculino } & \multicolumn{2}{c}{ feminino } \\
\cline { 2 - 5 } & média & erro padrão & média & erro padrão \\
\hline Exatas & 0,696 & 0,012 & 0,687 & 0,015 \\
\hline Engenharia & 0,583 & 0,007 & 0,634 & 0,011 \\
\hline Bio\&Saúde & 0,482 & 0,012 & 0,608 & 0,010 \\
\hline Humanas & 0,586 & 0,014 & 0,646 & 0,010 \\
\hline Artes & 0,575 & 0,021 & 0,620 & 0,018 \\
\hline Total & 0,578 & 0,005 & 0,633 & 0,005 \\
\hline
\end{tabular}


Presença feminina no estudo e no trabalho da ciência na Unicamp

\section{Nas grandes áreas:}

Por áreas de conhecimento onde a diferença é significativa do ponto de vista estatístico (tabela 9), destaca-se a maior diferença a favor das mulheres na área de ciências biológicas e da saúde (posto final médio mais de $25 \%$ maior que o dos colegas), sendo também grande nas ciências exatas e nas engenharias. Assim mesmo, essas diferenças são bastante inferiores às que se registram na amostra total, onde as alunas de bio\&saúde chegam quase $40 \%$ à frente dos estudantes homens, as engenheiras $20 \%$ e as formadas em ciências humanas $23 \%$.

Bio\&Saúde - Mulheres tem Posto Final 26,1\% maior que os homens

Engenharia - Mulheres tem Posto Final 8,4\% maior que os homens

Humanas - Mulheres tem Posto Final $\mathbf{1 0 , 2} \%$ maior que os homens

Tabela 9

Teste t para a comparação do posto final médio entre os sexos por área

\begin{tabular}{lcc}
\hline Área & \multicolumn{2}{c}{ Teste $\mathrm{t}$} \\
\hline & $\mathrm{t}$ & $\mathrm{p}$-valor \\
\hline Bio\&Saúde & $-7,984$ & 0,0000 \\
\hline Exatas & 0,471 & 0,6380 \\
\hline Engenharia & $-4,067$ & 0,0001 \\
\hline Humanas & $-3,445$ & 0,0006 \\
\hline Artes & $-1,628$ & 0,1046 \\
\hline Total & $-7,497$ & 0,0000 \\
\hline
\end{tabular}

\section{Cursos mais concorridos:}

Também nos cursos mais concorridos da Unicamp verificase que o posto final das mulheres é significativamente superior ao dos homens. Essa distância é maior, possivelmente, pelos mesmos motivos já apontados, na amostra total, que inclui jubilados e os que abandonaram o curso, naqueles cursos em que a diferença é significativa ao nível de $5 \%$ nas duas amostras. A única exceção é 
o curso de odontologia, no qual a distância é um pouco maior na amostra só de formados.

\section{Amostra total:}

Medicina Mulheres tem Posto Final $\mathbf{3 5 , 5 \%}$ maior que os Homens.

Odontologia Mulheres tem Posto Final 18,0\% maior que os Homens.

Biologia Diurno Mulheres tem Posto Final 20,1\% maior que os Homens.

Ciência Computação.............. Mulheres tem Posto Final 28,7\% maior que os Homens.

Eng. da Computação .............. Mulheres tem Posto Final $\mathbf{3 0 , 7 \%}$ maior que os Homens.

Eng. de Alimentos .................. Mulheres tem Posto Final 23,2\% maior que os Homens.

Enfermagem.......................... Mulheres tem Posto Final $\mathbf{6 3 , 2} \%$ maior que os Homens.

Ciências Econômicas D........... Mulheres tem Posto Final 25,2\% maior que os Homens.

\section{Amostra só formados}

Medicina Mulheres têm Posto Final $\mathbf{3 0 , 7} \%$ maior.

Odontologia Mulheres têm Posto Final 19,9\% maior.

Ciência Computação.............. Mulheres têm Posto Final 28,1\% maior.

Eng. da Computação ............. Mulheres têm Posto Final 18,2\% maior.

Eng. de Alimentos Mulheres têm Posto Final 17,6\% maior.

Ciências Econômicas D.......... Mulheres têm Posto Final 24,0\% maior. 
Presença feminina no estudo e no trabalho da ciência na Unicamp

Esses resultados apontam para o fato de que, além do sexo, há outras diferenças que se estabelecem entre amostras masculinas e femininas. Algumas delas estão vinculadas à socialização de meninos e meninas - que estão na base da escolha diferenciada de carreiras. A competitividade é estimulada nos meninos desde pequenos, enquanto a colaboração no trabalho familiar marca a infância das meninas. Outras se referem ao papel que desempenham na vida familiar, que conduzem muitas vezes à maior solicitação de envolvimento dos homens no suprimento de recursos para o orçamento doméstico, o que explicaria o maior índice de abandono dos cursos e de jubilados.

\subsection{Percentual de alunos que concluem o curso, por sexo}

A distribuição dos alunos segundo a situação acadêmica na Unicamp, e sexo, mostra que a percentagem de meninas formadas é quase $11 \%$ maior que a de meninos $(78,9 \%$ e $68,0 \%$ respectivamente) (tabela 10). A diferença é estatisticamente significativa. ${ }^{13}$ Esse fator pode estar por trás de parte da diferença de rendimento ao longo do curso, por sexo. Mais adiante serão levantadas algumas hipóteses sobre esse comportamento diferenciado quanto à conclusão dos cursos.

Tabela 10

Distribuição dos alunos segundo situação e sexo

\begin{tabular}{lrrrrrr}
\hline \multirow{2}{*}{ Situação } & \multicolumn{4}{c}{ Sexo } & \multicolumn{2}{c}{ Total } \\
\cline { 2 - 5 } & \multicolumn{2}{c}{ Masculino } & \multicolumn{2}{c}{ Feminino } & & \multicolumn{1}{c}{ \% } \\
\cline { 2 - 5 } & \multicolumn{1}{c}{$\mathrm{n}$} & \multicolumn{1}{c}{$\mathrm{n}$} & \multicolumn{1}{c}{$\mathrm{n}$} & $\%$ \\
\hline jubilado & 1.178 & 29,1 & 517 & 20,0 & 1.695 & 25,5 \\
formado & 2.754 & 68,0 & 2.043 & 78,9 & 4.797 & 72,2 \\
ativo & 119 & 2,9 & 30 & 1,2 & 149 & 2,2 \\
\hline Total & 4.051 & 100,0 & 2.590 & 100,0 & 6.641 & 100, \\
\hline
\end{tabular}

${ }^{13}$ Foi aplicado o teste de qui-quadrado o p-valor encontrado foi 0,0000 (Qui = $99,7253)$, portanto a diferença é significativa ao nível de $5 \%$. 
A distribuição da amostra de acordo com a área e a situação do aluno para os sexos masculino e feminino, respectivamente, mostra que a porcentagem de alunos formados é maior entre as mulheres, comparada à dos homens, em todas as áreas e não apenas na média geral (figura 1). Houve diferença significativa ao nível de 5\% nas áreas de ciências exatas, engenharias e ciências humanas. Nas ciências biológicas e da saúde, assim como nas artes, não há diferenças significativas entre os sexos no percentual de alunos que concluem o curso. Essas áreas são as de maior percentual de formados na Unicamp.

Nas exatas, apenas $38 \%$ dos homens haviam se formado, contra $65,2 \%$ das mulheres: é a maior diferença revelada dessa variável por sexo. Nas engenharias, essas percentagens são $76,1 \%$ e $81,3 \%$, respectivamente, e o porcentual de homens ativos (alunos que ainda não haviam concluído o curso) é $4,9 \%$ e o de mulheres apenas $2 \%$. As engenharias parecem exigir maior tempo médio para conclusão dos cursos em relação ao sugerido no currículo, pois registram o maior percentual de ativos de toda a amostra. Nas humanas, a diferença entre os concluintes é também expressiva: a percentagem dos homens já formados é de 65,4 e a das mulheres $72,5 \%$.

A distribuição da amostra entre os cursos diurnos e noturnos segundo a área e a situação do aluno, para o sexo masculino $e$ feminino revela, como seria de se esperar, que os percentuais de conclusão de curso do diurno são mais elevados que os do noturno em todas as áreas. Nas ciências exatas, por exemplo, enquanto os formados representam $43 \%$ dos alunos do diurno, para os homens, são apenas $22 \%$ entre os do período noturno. 
Presença feminina no estudo e no trabalho da ciência na Unicamp

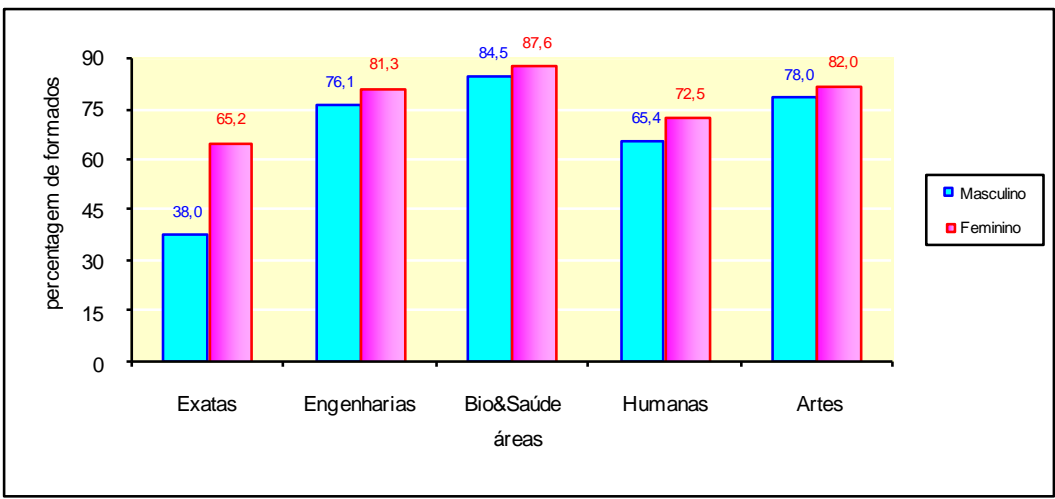

Figura 1 - Distribuição dos alunos por sexo segundo a situação por área

No caso das alunas de exatas, os percentuais são $67 \%$ no diurno e $48 \%$ no noturno, mantendo uma expressiva diferença por sexo em cada período. Ainda assim, a comparação por área fica prejudicada, pois nem todas as carreiras oferecem curso noturno não existe nas artes, são poucas nas engenharias e na bio\&saúde não inclui medicina, curso mais numeroso da área.

Entre os cursos diurnos houve diferença significativa por sexo nas áreas de exatas e engenharias, e nos cursos noturnos nas áreas de exatas, bio\&saúde e humanas. Em todos os casos, as mulheres apresentam maior percentagem de formados do que os homens.

Quando se estratifica a amostra para incluir apenas os cursos mais concorridos nas diferentes áreas, por sexo, revela-se que a Medicina apresentou maior percentagem de formados, $94,1 \%$ dos homens e $97,5 \%$ das mulheres. O curso com menor percentagem de formados foi História Diurno, com $61,5 \%$ de homens e $66,7 \%$ de mulheres (figura 2). Mas não houve diferença significativa entre os sexos em nenhum desses cursos avaliados (no caso da Enfermagem, em que a diferença é maior, o reduzido número de alunos homens não conduz a uma diferença estatisticamente significativa). 
O tempo relativo médio ${ }^{14}$ para conclusão (incluídos apenas os formados) dos cursos mais disputados por área não apresentou diferença significativa entre os sexos em nenhum caso (tabela 11).

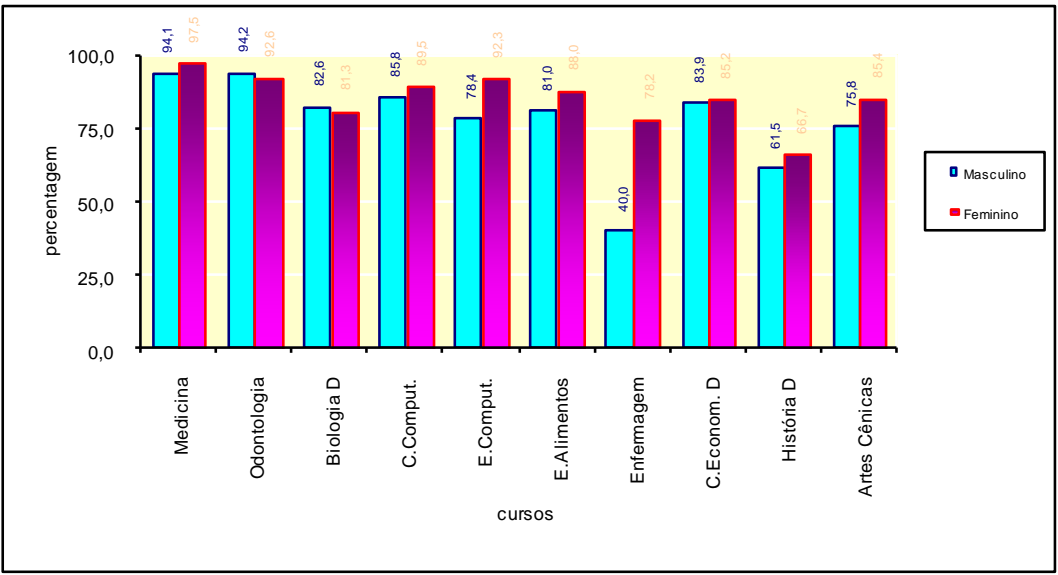

Figura 2 - Percentagem de alunos formados por curso e por sexo

Pode-se supor, portanto, que parte da diferença encontrada por grande área entre os sexos deve-se à composição diferenciada de cursos, por sexo, e também à diferença de percentual de jubilados, que já se revelou bastante diferenciada entre alunos $e$ alunas.

\footnotetext{
${ }^{14} \mathrm{O}$ tempo relativo de permanência na Unicamp foi calculado a partir da razão entre o tempo total que o aluno permanece na universidade (em semestres) e o tempo mínimo de conclusão do curso previsto pela universidade.
} 
Presença feminina no estudo e no trabalho da ciência na Unicamp

Tabela 11

Médias e Erro Padrão do tempo de permanência relativo por sexo nos cursos selecionados

\begin{tabular}{lcccc}
\hline \multicolumn{4}{c}{ Masculino } & \multicolumn{2}{c}{ Feminino } \\
\hline Cursos & média & erro padrão & média & erro padrão \\
\hline Medicina & 0.940 & 0.004 & 0.937 & 0.004 \\
\hline Odontologia & 1.026 & 0.008 & 1.016 & 0.005 \\
\hline Biologia D & 1.063 & 0.033 & 1.042 & 0.018 \\
\hline Ciência da Computação & 1.082 & 0.024 & 0.993 & 0.023 \\
\hline Eng. da Computação & 1.071 & 0.012 & 1.000 & 0.016 \\
\hline Eng. de Alimentos & 1.109 & 0.013 & 1.081 & 0.010 \\
\hline Enfermagem & 1.000 & 0.000 & 1.049 & 0.014 \\
\hline Ciências Econômicas D & 1.204 & 0.022 & 1.147 & 0.021 \\
\hline História D & 1.245 & 0.061 & 1.148 & 0.025 \\
\hline Artes Cênicas & 1.180 & 0.056 & 1.161 & 0.040 \\
\hline A méda é
\end{tabular}

A média é estimada pelo tempo real médio para conclusão sobre o tempo previsto.

No caso do aluno concluir o curso no tempo previsto o índice é igual a 1.

\section{Jovens que trabalham antes de entrar na universidade e seu rendimento acadêmico}

A percentagem de alunos que trabalhavam antes de entrar na universidade por área e por sexo, para os alunos formados $e$ jubilados ou desistentes, permite a formulação de algumas hipóteses explicativas relativa ao percentual de jubilados (maior para os homens) e de formados (maior no caso das alunas). A área de artes apresentou maior percentagem de alunos que trabalhavam, seguida pelas humanas e pelas exatas. A percentagem de rapazes que trabalhavam é superior à de mulheres em todas as áreas. Entre os rapazes, a percentagem dos formados que trabalhavam é menor do que a de jubilados na mesma situação, com exceção das artes, onde, aparentemente, o trabalho não afeta negativamente o desempenho acadêmico. Entre as moças, nas áreas de engenharias, humanas e artes, a diferença entre as percentagens das formadas e jubiladas que 
trabalhavam é pequena. Nas exatas, $21,2 \%$ das garotas que se formaram trabalhavam antes de entrar na universidade e apenas $14,6 \%$ das jubiladas; na área de bio\&saúde acontece o inverso, $14,3 \%$ e $21,5 \%$ das garotas que se formaram e das que foram jubiladas, respectivamente, trabalhavam antes de ingressar na Unicamp (figura 3).

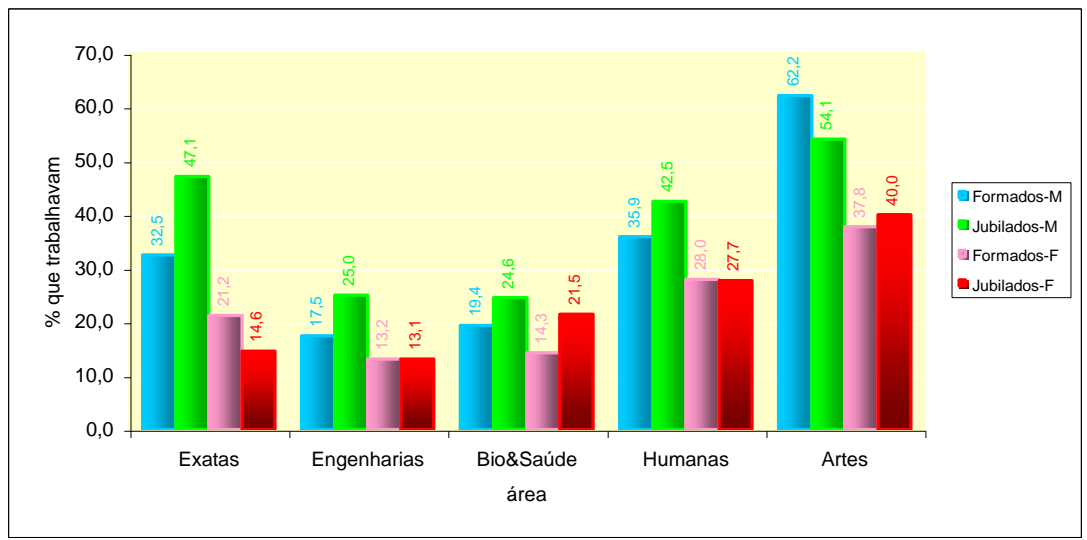

Figura 3 - Gráfico da percentagem de alunos que trabalhavam antes de entrar na universidade por área, segundo situação acadêmica e sexo

A participação econômica do aluno, comparada ao seu rendimento acadêmico, é melhor visualizada pela distribuição dos estudantes segundo a participação do aluno no sustento da família $e$ sua situação acadêmica. A situação acadêmica foi dividida em dois grupos: formados e não formados (jubilados, desistentes $e$ ativos). Os ativos foram colocados junto com os jubilados, por serem poucos (151 alunos) e não afetarem significativamente o resultado.

Os não formados apresentam maiores percentagens de jovens que trabalhavam e recebiam ajuda da família, trabalhavam e não recebiam ajuda, trabalhavam e ajudavam em casa e os que eram responsáveis pelo sustento da casa. Entre os alunos formados é maior a percentagem dos que não trabalhavam 
Presença feminina no estudo e no trabalho da ciência na Unicamp

(77,5\%), com relação aos não formados (66,5\%) (tabela 12). As diferenças foram significativas ao nível de $5 \%$ ( $p$-valor $=0,000)$.

Tabela 12

Distribuição da amostra segundo a participação econômica do aluno na família e a situação acadêmica

\begin{tabular}{lccc}
\hline \multirow{2}{*}{$\begin{array}{c}\text { Participação Econômica na } \\
\text { Família }\end{array}$} & \multicolumn{2}{c}{ Situação acadêmica } & \multirow{2}{*}{ Total } \\
\cline { 2 - 4 } & não formado & formado & \\
\hline não trabalha & 66.5 & 77.5 & 74.4 \\
\hline trabalha/recebe ajuda & 17.6 & 14.6 & 15.5 \\
\hline trabalha/não recebe ajuda & 7.0 & 3.8 & 4.7 \\
\hline trabalha/ajuda família & 5.7 & 3.1 & 3.8 \\
\hline responsável p/ sustento da casa & 3.2 & 1.0 & 1.6 \\
\hline Total & 100.0 & 100.0 & 100.0 \\
\hline
\end{tabular}

Esses fatores ajudam a entender a diferenciação por sexo no coeficiente de rendimento dos alunos como parte de um quadro social em que ao homem ainda cabe maior carga de responsabilidade em relação ao sustento da família. Esse distanciamento só não é maior porque, na universidade em questão, três quartos dos alunos não trabalhavam quando nela ingressaram.

\section{Diferenças por sexo na distribuição da renda familiar dos ingressantes}

A distribuição da amostra não registrou diferença significativa na distribuição da renda mensal familiar entre os sexos, para os calouros da universidade (Qui $=2,2701$ e p-valor $=$ 0,518) (tabela 13). 
Elza Vasconcellos e Sandra Brisolla

Tabela 13

Distribuição dos alunos segundo renda familiar mensal e sexo

\begin{tabular}{lrrrrrr}
\hline \multirow{2}{*}{\begin{tabular}{c} 
Renda mensal $\begin{array}{c}\text { familiar } \\
\text { (em sal. mínimo) }\end{array}$ \\
\cline { 2 - 6 }
\end{tabular}} & \multicolumn{2}{c}{ Masculino } & \multicolumn{2}{c}{ Feminino } & \multicolumn{2}{c}{ Total } \\
\hline até 3 & 113 & 2,9 & 62 & 2,5 & 175 & 2,7 \\
\hline de 3 a 10 & 896 & 22,6 & 601 & 24,0 & 1.497 & 23,2 \\
\hline de 10 a 20 & 1.28 & 32,4 & 800 & 31,9 & 2.085 & 32,3 \\
\hline acima de 20 & 1.66 & 42,1 & 1.041 & 41,6 & 2.707 & 41,9 \\
\hline Total & 3.96 & 100,0 & 2.504 & 100,0 & 6.464 & 100,00 \\
\hline
\end{tabular}

No entanto, na comparação por área, foram encontradas diferenças significativas entre os sexos, ao nível de 5\%, apenas na área de bio\&saúde. Os rapazes contam com famílias de níveis de renda mais elevados (figura 4 ).

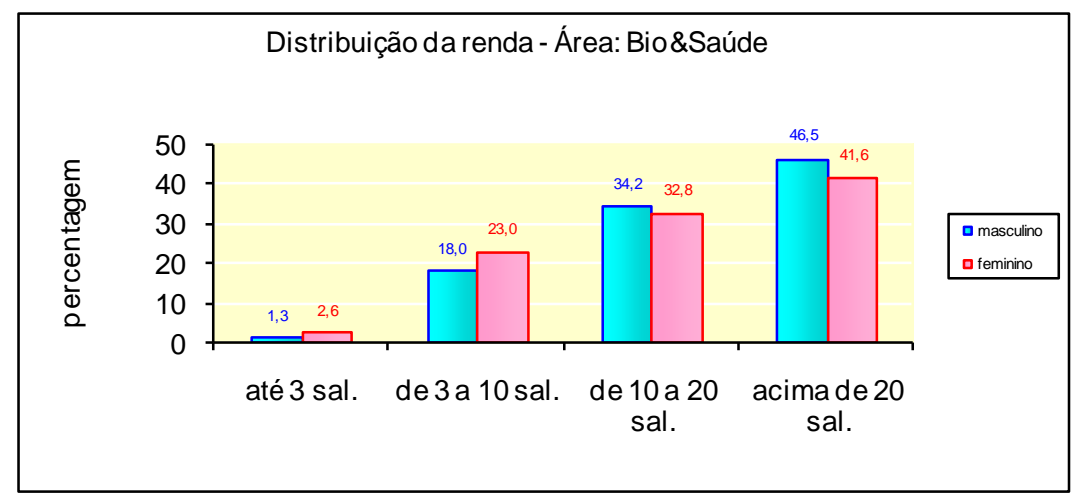

Figura 4 - Distribuição da renda mensal segundo sexo para alunos da área de bio\&saúde

Já entre os cursos pertencentes à área de bio\&saúde, houve diferença significativa entre os sexos, com relação à distribuição de renda no curso de Enfermagem e no curso de biologia noturno (figuras 5 e 6). Em ambos os casos, a presença dos homens em faixas de renda maiores é superior à presença de mulheres. Mas a faixa de renda entre 10 e 20 salários mínimos é muito mais 
Presença feminina no estudo e no trabalho da ciência na Unicamp

presente nas famílias dos estudantes do sexo masculino, em ambos os casos. A distribuição de renda segundo o sexo para o curso de medicina (mais disputado) não é significativa, mas nessa carreira homens e mulheres pertencem a famílias com maior concentração de renda: cerca de $60 \%$ dessas famílias tem renda mensal acima de 20 salários mínimos (figura 7).

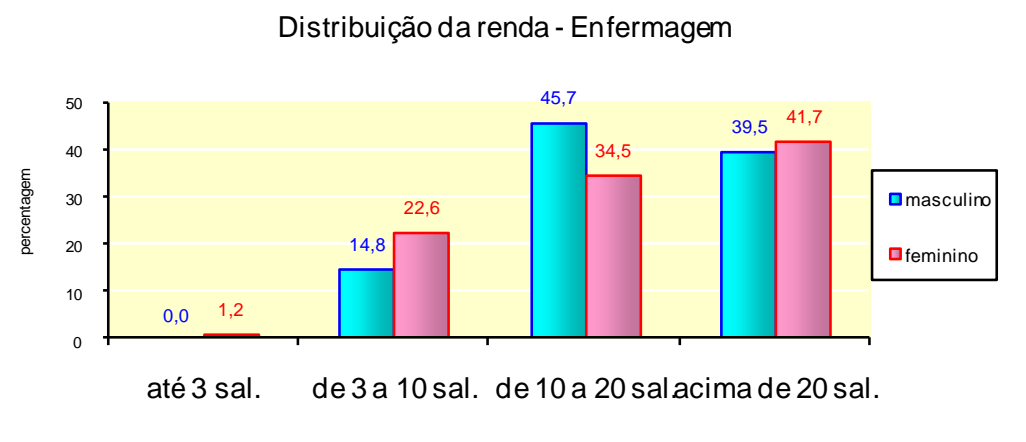

Figura 5 - Distribuição da renda familiar mensal segundo sexo para os alunos do curso de enfermagem

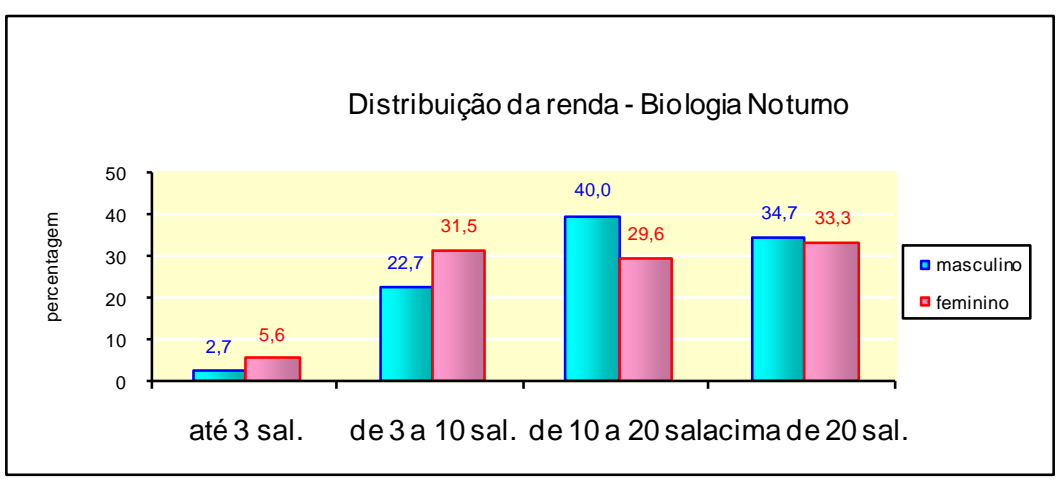

Figura 6 - Distribuição da renda familiar mensal segundo sexo para os alunos do curso de biologia noturno 


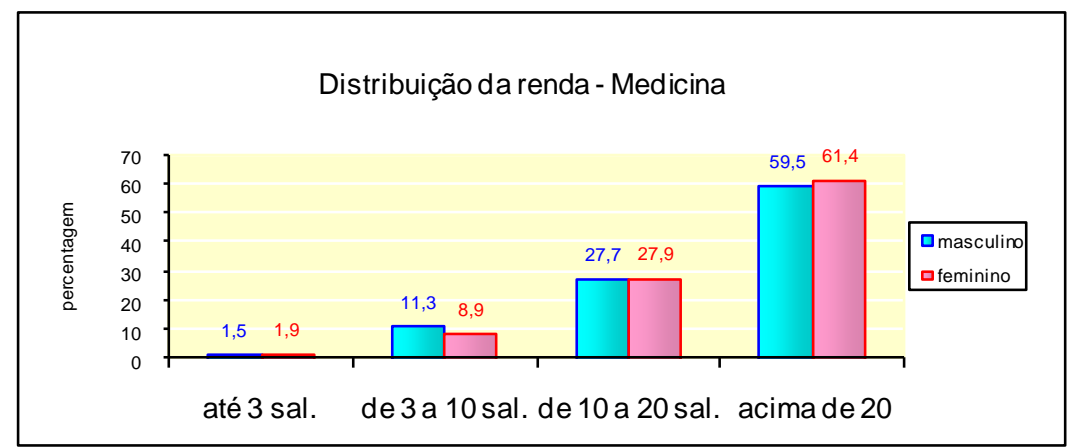

Figura 7 - Distribuição da renda familiar mensal segundo sexo para os alunos do curso de medicina

\section{Além da renda, é importante o nível de instrução dos pais}

Tampouco há diferença significativa na distribuição do nível de instrução do pai entre os sexos, para os cursos selecionados por critério de maior procura - o teste de qui-quadrado revelou não haver diferença estatisticamente significativa em nenhum deles. No entanto, existe bastante diferença entre os cursos em relação à percentagem de pais com curso superior. Entre os avaliados, medicina e engenharia de alimentos são os cursos com os maiores índices de alunos com pais que cursaram o ensino superior; enfermagem é o curso de menores índices nesse particular. Assim mesmo, em medicina, engenharia de alimentos $e$ artes cênicas, o percentual de pais com curso superior é maior entre as alunas que entre os homens ingressantes na universidade, o que é revelador da influência do pai, no caso de escolha de carreiras das hard sciences, principalmente para as mulheres. No caso da enfermagem, o número de alunos do sexo masculino é muito pequeno para que se possa fazer qualquer observação. Mas chama a atenção o fato de nenhum dos alunos homens ter pai com nível superior, quando quase $40 \%$ das suas colegas têm (figura 8). 
Presença feminina no estudo e no trabalho da ciência na Unicamp

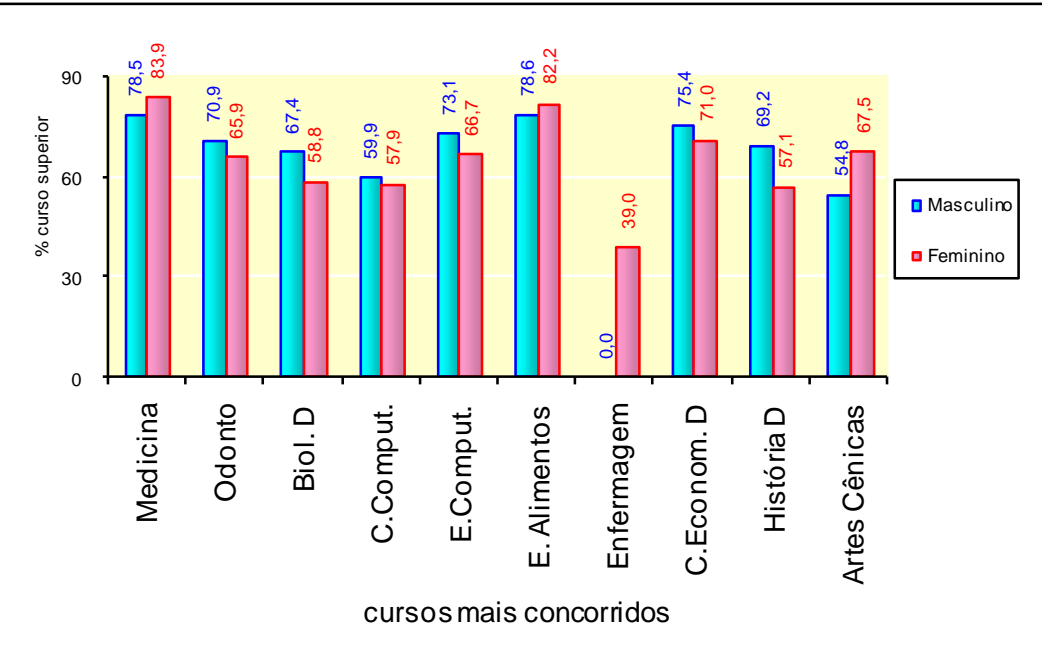

Figura 8 - Percentagem de pais que possuem curso superior, por curso e por sexo

Mas é no nível de instrução da mãe que se mede mais adequadamente a influência da formação dos pais. Não houve diferença significativa ao nível de $5 \%$ em nenhum dos cursos selecionados, com relação ao sexo. A percentagem de alunos/as com mães que cursaram ensino superior é menor do que a de alunos/as com pais com essa formação, salvo no caso de artes cênicas (compare-se a figura $8 \mathrm{com}$ a figura 9). 


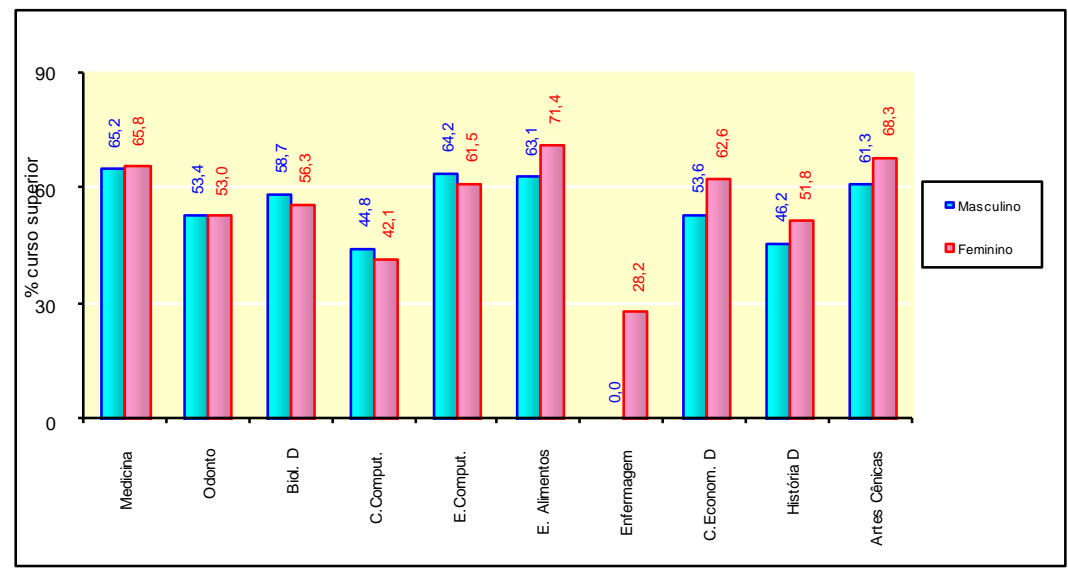

Figura 9 - Percentagem de mães que possuem curso superior, por curso $e$ por sexo

Por outro lado, é mais comum entre os cursos selecionados o fato das alunas terem um percentual maior de mães com nível superior do que seus colegas homens: isso ocorre na medicina, na engenharia de alimentos, nas artes cênicas e na enfermagem (como ocorre com os percentuais de pais com nível superior), mas também nas ciências econômicas (diurno) e na história (diurno) (figura 9).

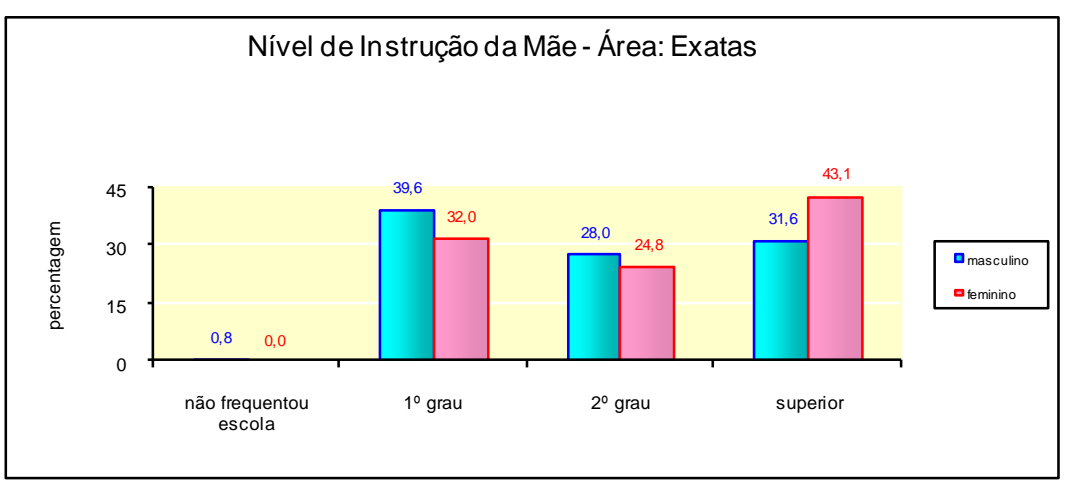

Figura 10 
Presença feminina no estudo e no trabalho da ciência na Unicamp

Quando se compara o nível de instrução do pai e da mãe por sexo para as áreas exatas e as engenharias, verifica-se que a diferença entre as alunas com mães de nível superior e dos alunos com mães com essa formação é mais elevada do que a mesma diferença em relação ao pai com nível superior. Assim, $43,1 \%$ das alunas e $31,6 \%$ dos alunos da área de exatas têm mãe com nível superior (diferença de 11,5\%) (figura 10).

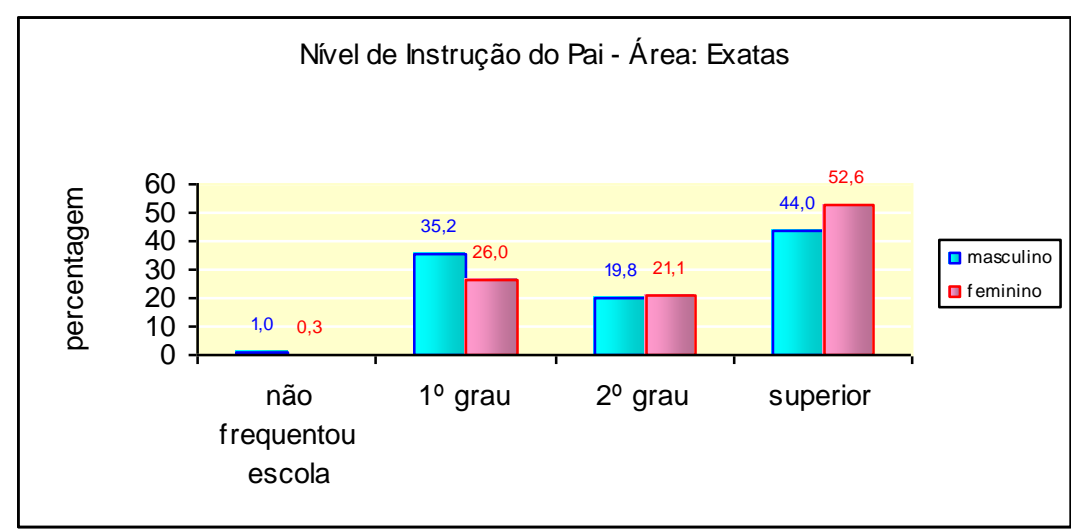

Figura 11

Nessa área, por outro lado, $52,6 \%$ das alunas e $44 \%$ dos alunos têm pai com nível superior (diferença de 8,6\%) (figura 11). O mesmo ocorre na área das engenharias $(71,9 \%$ das alunas $e$ $66,2 \%$ dos alunos têm pai com nível superior $-5,7 \%$ de diferença) (figura 13), enquanto $60,2 \%$ das alunas e $53,1 \%$ dos alunos têm mãe com nível superior (7,1\% de diferença) (figura 12). 


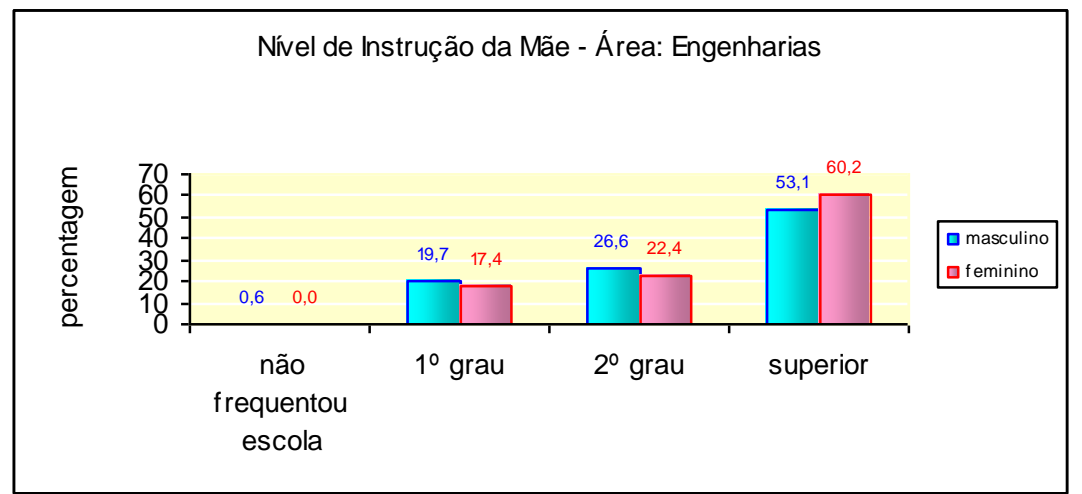

Figura 12.

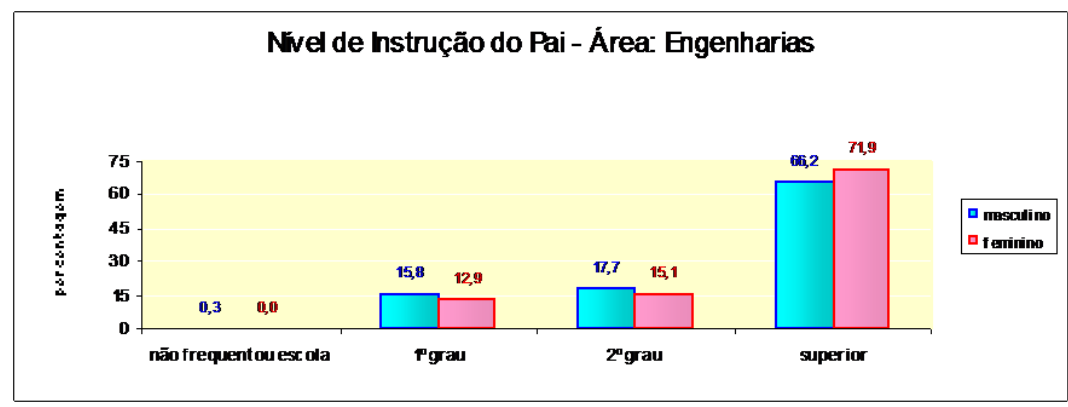

Figura 13.

Os dados mostram que não apenas a presença de pais (tanto pai como mãe) com nível superior é mais importante como fator de escolha das carreiras exatas e tecnológicas para as mulheres do que para os homens, mas também que é maior a influência do fato de ter mãe com nível superior sobre as mulheres do que sobre os homens, que se identificam mais com o pai.

\section{Diferença de motivação para escolha da carreira}

Houve diferença significativa, ao nível de 5\%, na distribuição do motivo de escolha da carreira entre os sexos apenas no curso de ciência da computação e engenharia da 
Presença feminina no estudo e no trabalho da ciência na Unicamp

computação, dentre os cursos mais concorridos (teste de quiquadrado na tabela 14).

Em ciência da computação, $54,9 \%$ dos homens indicaram a opção "sempre gostou" e $42,1 \%$ "aptidão pessoal". Entre as mulheres, 47,4\% indicaram a opção "sempre gostou" e 47,4\% "aptidão pessoal". Em engenharia da computação, também os homens apresentam maior percentagem para "sempre gostou", comparados às mulheres $(47,9 \%$ e $25,6 \%$ respectivamente) e menor porcentagem para "aptidão pessoal" $(45,1 \%$ e $64,1 \%$ respectivamente) (tabela 15 ).

\section{Tabela 14}

Teste Qui-quadrado para avaliar se há diferença entre os sexos quanto ao motivo de escolha da carreira por cursos

\begin{tabular}{lcc}
\hline \multirow{2}{*}{ Cursos } & \multicolumn{2}{c}{ Teste } \\
\cline { 2 - 3 } & $\square^{2}$ & p-valor \\
\hline Medicina & 4,71 & 0,1940 \\
\hline Odontologia & 6,36 & 0,0950 \\
\hline Biologia D & 3,92 & 0,2700 \\
\hline Ciência da Comput. & 7,85 & 0,0490 \\
\hline Eng. da Comput. & 9,95 & 0,0190 \\
\hline Eng. de Alimentos & 6,29 & 0,0980 \\
\hline Enfermagem & 5,17 & 0,1600 \\
\hline Ciências Econom. D & 2,51 & 0,4730 \\
\hline História D & 0,89 & 0,8290 \\
\hline Artes Cênicas & 0,26 & 0,6090 \\
\hline
\end{tabular}

Como esses motivos são bastante relacionados entre si, fica difícil explicar a diferença na opção entre eles, verificável por sexo, nos dois casos. Em todo caso, é claro que a aptidão pessoal, facilidade de apreensão de conhecimentos em carreiras percebidas como tradicionalmente masculinas (e estão incluídas nas hard sciences) - mais evidente nas engenharias do que nas ciências exatas - pesa mais na escolha das mulheres, talvez porque o gosto por essas áreas não seja estimulado na infância das meninas. Assim mesmo, apenas esses dois, entre os dez cursos selecionados, mostraram diferença significativa entre os sexos quanto ao motivo 
Elza Vasconcellos e Sandra Brisolla

de sua escolha, o que recomenda cautela na explicação dessa variável.

Tabela 15

Distribuição da amostra segundo sexo e motivo de escolha da carreira para os cursos de ciência da computação e eng. Computação

\begin{tabular}{lrrrr}
\hline \multirow{2}{*}{$\begin{array}{c}\text { Motivo de escolha } \\
\text { da carreira }\end{array}$} & \multicolumn{4}{c}{ Cursos } \\
\cline { 2 - 5 } & \multicolumn{2}{c}{ C. Computação } & \multicolumn{2}{c}{ Eng. Computação } \\
\cline { 2 - 5 } & Masc. & Fem. & Masc. & Fem. \\
\hline sempre gostou & 54,9 & 47,4 & 47,9 & 25,6 \\
\hline aptidão pessoal & 42,1 & 47,4 & 45,1 & 64,1 \\
\hline meios de comunicação & 0,0 & 5,3 & 4,6 & 2,6 \\
\hline outro & 3,0 & 0,0 & 2,5 & 7,7 \\
\hline Total & 100,0 & 100,0 & 100,0 & 100,0 \\
\hline
\end{tabular}

\section{Disponibilidade de micro-computador em casa por sexo}

A diferença na percentagem de alunos que têm micro em casa por sexo foi significativa, ao nível de $5 \%$, apenas no curso de engenharia da computação - 77,2\% dos rapazes e apenas $46,2 \%$ das alunas ingressantes declararam ter micro em casa (figura 14).

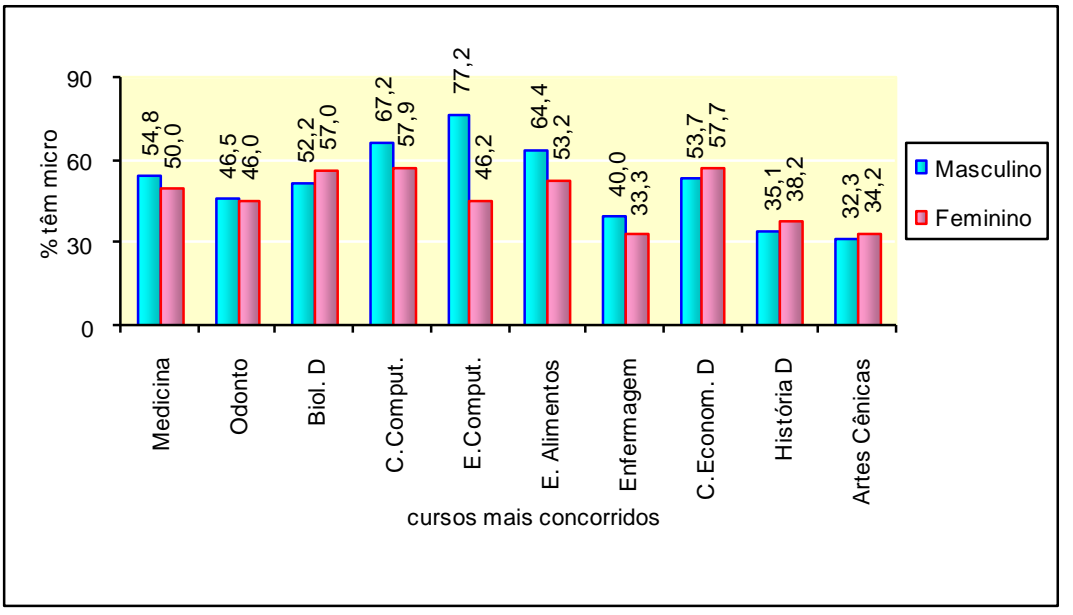

Figura 14 - Percentagem de alunos que tem micro em casa, por curso e por sexo 
Presença feminina no estudo e no trabalho da ciência na Unicamp

O fato de ter micro em casa afeta o motivo da escolha da carreira. Assim, responderam "sempre gostou" da carreira, em maior percentagem, os alunos (de ambos os sexos) que dispõem do microcomputador em casa.

Tabela 16

Distribuição da amostra segundo o motivo de escolha da carreira e se tem ou não micro em casa - Amostra total

\begin{tabular}{lrrr}
\hline \multirow{2}{*}{ Motivo de Escolha Carreira } & \multicolumn{2}{c}{ Tem micro } & \multirow{2}{*}{ Total } \\
\cline { 2 - 3 } & \multicolumn{1}{c}{ Sim } & Não & \\
\hline Sempre gostou & 40,9 & 36,2 & 38,5 \\
\hline Aptidão pessoal & 49,3 & 52,5 & 50,9 \\
\hline Meios de comunicação & 4,0 & 4,5 & 4,3 \\
\hline Outros & 5,8 & 6,8 & 6,3 \\
\hline Total & 100,0 & 100,0 & 100,0 \\
\hline
\end{tabular}

No caso das respostas que indicam a escolha por "aptidão pessoal", os alunos que não têm micro em casa são em maior percentual do que os que têm (tabela 16).

\section{No universo dos estudantes}

Pelos dados analisados pode-se supor que existe uma tendência geral, mas não regular, de acréscimo do número de alunas na universidade, e também em boa parte das chamadas hard sciences. Ainda assim, persistem tendências claras de escolha diferenciada de carreiras por sexo, que se devem em parte à socialização de meninos e meninas com perfis diferentes $e$ também a oportunidades desiguais no mercado de trabalho por função, além dos motivos ligados diretamente aos estigmas que estão por trás de atitudes discriminatórias. Também vimos a influência da formação dos pais - e principalmente da mãe, no caso das meninas - na escolha do curso.

Apesar de menos numerosas na entrada na universidade, as alunas apresentam desempenho superior aos estudantes homens, 
nos diferentes cursos, por motivos diversos. Entre eles, analisamos a diferença de funções exercidas por jovens no sustento da casa, segundo o sexo, que provoca maior índice de desistência e de jubilados entre os alunos, em comparação com as estudantes.

Como resultado geral, pode-se apontar que jovens do sexo masculino e feminino têm as mesmas condições para cursar qualquer carreira universitária, devendo-se o predomínio de homens entre os alunos à composição de carreiras na Unicamp, que atraem mais candidatos do que candidatas. Já no conjunto do ensino superior brasileiro, incluindo as instituições de ensino superior privadas, onde os cursos de ciências humanas são muito mais numerosos, predominam as mulheres. $\mathrm{O}$ contrário acontece com os cursos técnicos e tecnológicos, que em nosso sistema ainda ocupam um espaço muito restrito na oferta de vagas do ensino superior.

Essa preferência reflete uma socialização diferenciada, resultante de hábitos culturais ainda marcados por funções que homens e mulheres desempenharam tradicionalmente na família $e$ na sociedade, e que vem se modificando aceleradamente na atualidade.

Este trabalho não pretende esgotar a análise dos fatores que podem explicar a diferença de desempenho entre os sexos na universidade, mas sim dar conta de alguns deles, de acordo com a disponibilidade das informações analisadas, e apontar para o fato de que estudantes são homens e mulheres, condicionados por comportamentos pautados por condutas sancionadas pela sociedade que influem, de diferentes maneiras, sobre esses resultados. Isso não deve conduzir à conclusão de que essas diferenças permeiam toda a sociedade, pois se trata de uma amostra limitada que não permite grandes generalizações.

Há, no entanto, uma evidência clara nos dados, apontando para o fato de que homens e mulheres são igualmente capazes de seguir carreiras das ciências mais diversas. O maior fluxo de homens para ciências exatas e tecnológicas se deve a questões de fundo cultural $e$ social $e$ não às possíveis capacidades inatas 
Presença feminina no estudo e no trabalho da ciência na Unicamp

diferenciadas por sexo. Além do condicionamento social, desempenham papel importante na escolha das carreiras as práticas ainda discriminatórias que afastam mulheres de profissões consideradas masculinas. O próprio ambiente de trabalho, nesses casos em que a presença feminina é consideravelmente reduzida, de certa forma, afasta a mulher e favorece atitudes sexistas.

O maior objetivo deste trabalho é chamar a atenção para o desperdício de recursos humanos mobilizáveis para a atividade científica, principalmente em países como o nosso, em que poderiam ter uma influência importante no tipo de desenvolvimento que se quer estimular. Se homens e mulheres pudessem responder ao apelo para a pesquisa e à ampliação do conhecimento com a mesma possibilidade e no mesmo nível, teríamos dobrado a capacidade de produzir ciência no país. Ciência que pode não apenas modificar o que se produz, senão também como se produz e com que homens, estabelecendo relações de cooperação que apontem para a superação dos problemas do subdesenvolvimento!

\section{Diferenças na progressão na carreira docente por gênero}

Nos dados que esta equipe está trabalhando, é interessante notar que a curva que corresponde à composição do corpo docente da Unicamp, em 1994, apresenta um perfil diferenciado por sexo (tabela 17 e figura 15). Acima do nível de doutor (MS-3), que constitui a maioria dos docentes, temos os livre-docentes (MS4) e professores adjuntos - ou associados, (MS-5) em ordem decrescente em número. Mas é no total de titulares (MS-6) que, inexplicavelmente, supera os MS-5 no caso dos homens, que se nota a preferência de que têm usufruído os homens para ascender a postos que exigem essa titularidade (sem entrar aqui na discussão das razões pelas quais isso ocorre), como as diretorias de institutos e faculdades, as pró-reitorias e cargos semelhantes. No caso das mulheres, a curva continua decrescente e o tamanho 
da discriminação pode ser medido pelo ângulo formado nesse último trecho das curvas dos dois sexos (figura 18). ${ }^{15}$

Figura 15

Docentes por nível acadêmico por gênero - 1994

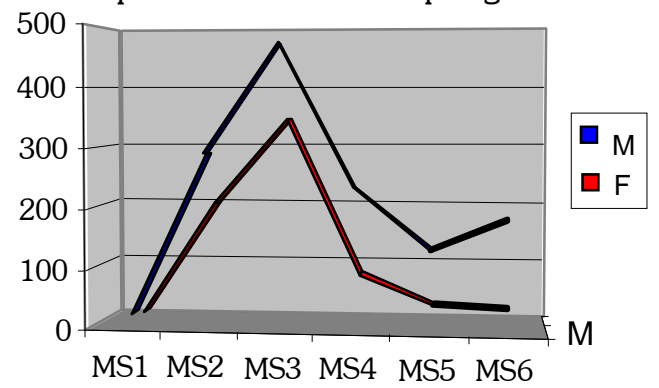

Fonte: Elaboração própria a partir dos dados da AEPLAN, Unicamp. Fonte: Anuário de Pesquisa 2005, Unicamp. O Gráfico inclui todos os docentes da Unicamp, em todos os regimes de contratação: MS-3 = Professor Doutor, MS-4 = Professor Livre-Docente, MS-5 $=$ Professor Adjunto, MS-6 = Professor Titular. No gráfico, $\mathrm{M}=$ Masculino e $\mathrm{F}=$ Feminino.

Tabela 17

Docentes em RDIDP - Doutores e maior titulação

Unicamp, 1994

\begin{tabular}{|c|c|c|c|c|c|}
\hline & & Nível & & & \multirow{2}{*}{ MS-6 } \\
\hline & MS-3 & MS-4 & MS-5 & MS-6 & \\
\hline Masculino & 403 & 215 & 124 & 166 & 89,7 \\
\hline Feminino & 329 & 78 & 27 & 19 & 10,3 \\
\hline
\end{tabular}

RDIDP = Regime de Dedicação Integral à Pesquisa e à Docência

Fonte: Anuário Estatístico 2005, Unicamp.

${ }^{15}$ Essa inversão de tendência que revela existirem mais professores titulares que adjuntos entre os docentes homens não é mais visível nos dados a partir de 2001, quando foram unificados os livre-docentes (MS-4) com os professores adjuntos (MS-5). Utilizamos os dados de 1994, por ser a primeira informação a ser trabalhada na série até 2004. 
Presença feminina no estudo e no trabalho da ciência na Unicamp

Figura 16

Docentes por sexo MS-3 a MS-6

Unicamp, 1994

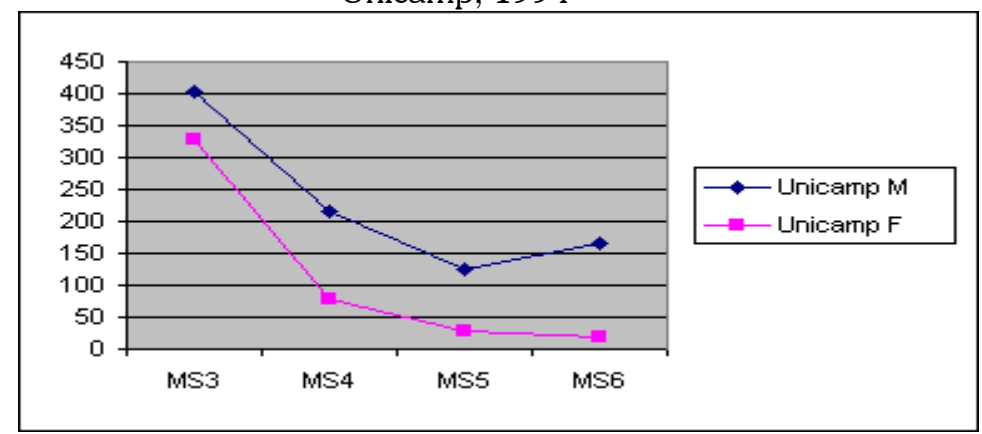

Fonte: Anuário Estatístico 2005, Unicamp

A figura 16, que utiliza informações apenas de titulados com doutorado (MS-3) ou acima desse nível, para 1994, mostra bem a diferença de comportamento da progressão na carreira entre homens e mulheres, principalmente quando o docente alcança maior nível acadêmico. No caso da Unicamp, a curva masculina sobe de MS-5 para MS-6, porque somente MS-6 (titulares) podem ocupar cargos de direção das unidades acadêmicas, onde os homens são ampla maioria.

Tabela 18

Docentes em RDIDP - Doutores e maior titulação

Unicamp, 2004

\begin{tabular}{lcccc} 
& \multicolumn{3}{c}{ RDIDP } & MS-6 \\
\hline & MS3 & MS5 & MS6 & \% por sexo \\
\hline Masculino & 354 & 375 & 205 & $78,20 \%$ \\
Feminino & 307 & 182 & 57 & $21,80 \%$ \\
\hline
\end{tabular}

RDIDP = Regime de Dedicação Integral à Pesquisa e à Docência

Fonte: Anuário Estatístico 2005, Unicamp.

Em 2004, o percentual de mulheres titulares (MS-6) na Unicamp é o dobro do de 1994 - de $10,3 \%$ passa para $21,8 \%$. No 
entanto, sem deixar de reconhecer o avanço nesses dez anos, ainda chama a atenção o fato de que havendo $15 \%$ mais homens do que mulheres doutores (MS-3) em 2004 e duas vezes mais homens livre-docentes (MS-5) do que mulheres, haja quatro vezes mais homens titulares (MS-6) do que mulheres em toda a universidade (tabela 18).

O Anuário Estatístico de 2007, com dados de 2006, revela o seguinte quadro da composição do corpo docente por gênero $e$ por nível (MS):

Tabela 19

Docentes em RDIDP - Doutores e maior titulação Unicamp, 2006

\begin{tabular}{lcccc}
\hline & MS-3 & Mível & MS-6 \\
& 462 & 393 & 252 & $76,8 \%$ \\
\hline Masculino & 335 & 174 & 76 & $23,2 \%$ \\
\hline
\end{tabular}

RDIDP = Regime de Dedicação Integral à Pesquisa e à Docência

Fonte: Anuário Estatístico 2005, Unicamp.

A diferença no número de docentes por gênero na Unicamp ainda é grande. Em 2006, a universidade contava com 1.761 docentes (da carreira de magistério superior $=\mathrm{MS}$ ) ativos, (cerca de $96 \%$ deles têm pelo menos doutorado), sendo 1.163 homens e 598 mulheres, o que significa que as docentes correspondiam a um terço do total do corpo acadêmico (34\%).

As mulheres, em 2006, são $42,0 \%$ dos docentes doutores (MS-3), 30,7\% dos livre-docentes (ou adjuntos, MS-5) e 23,2\% dos titulares (MS-6) (figura 17). Nota-se uma tendência de aumento da titulação das mulheres, principalmente quando se compara com a situação em 1994 (o percentual de mulheres titulares mais do que dobra em 2006 (de 10,3\% em 1994 passa a 21,8\% em 2004 e $23,15 \%$ em 2006), embora esteja longe do percentual de mulheres no total docente $(33,9 \%)$. 
Presença feminina no estudo e no trabalho da ciência na Unicamp

Figura 17

Docentes por nível acadêmico e por sexo

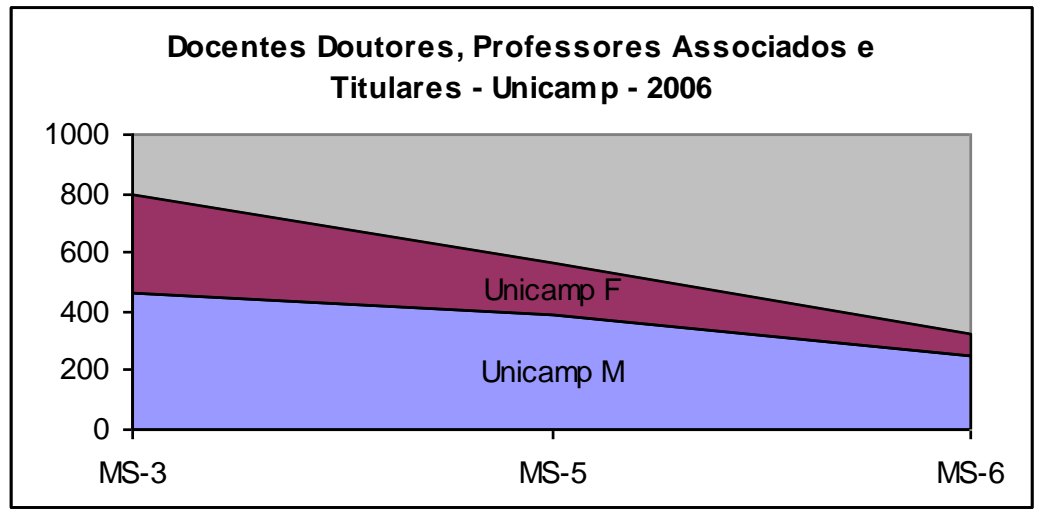

MS-3 - Professor Doutor; MS-5 - Professor Associado; MS-6 - Professor Titular Fonte: Anuário Estatístico da Unicamp - 2007

http://www.aeplan.unicamp.br/anuario_estatistico_2007/index.htm

A caracterização da relação de gênero no corpo de professores da Unicamp pode ser abordada a partir de estatísticas da composição docente por nível acadêmico e por grandes áreas de conhecimento, e sua evolução ao longo do tempo.

Aqui se apresenta um pequeno exercício com dados bem gerais do contingente de professores da Unicamp. 


\section{Situação em 2001}
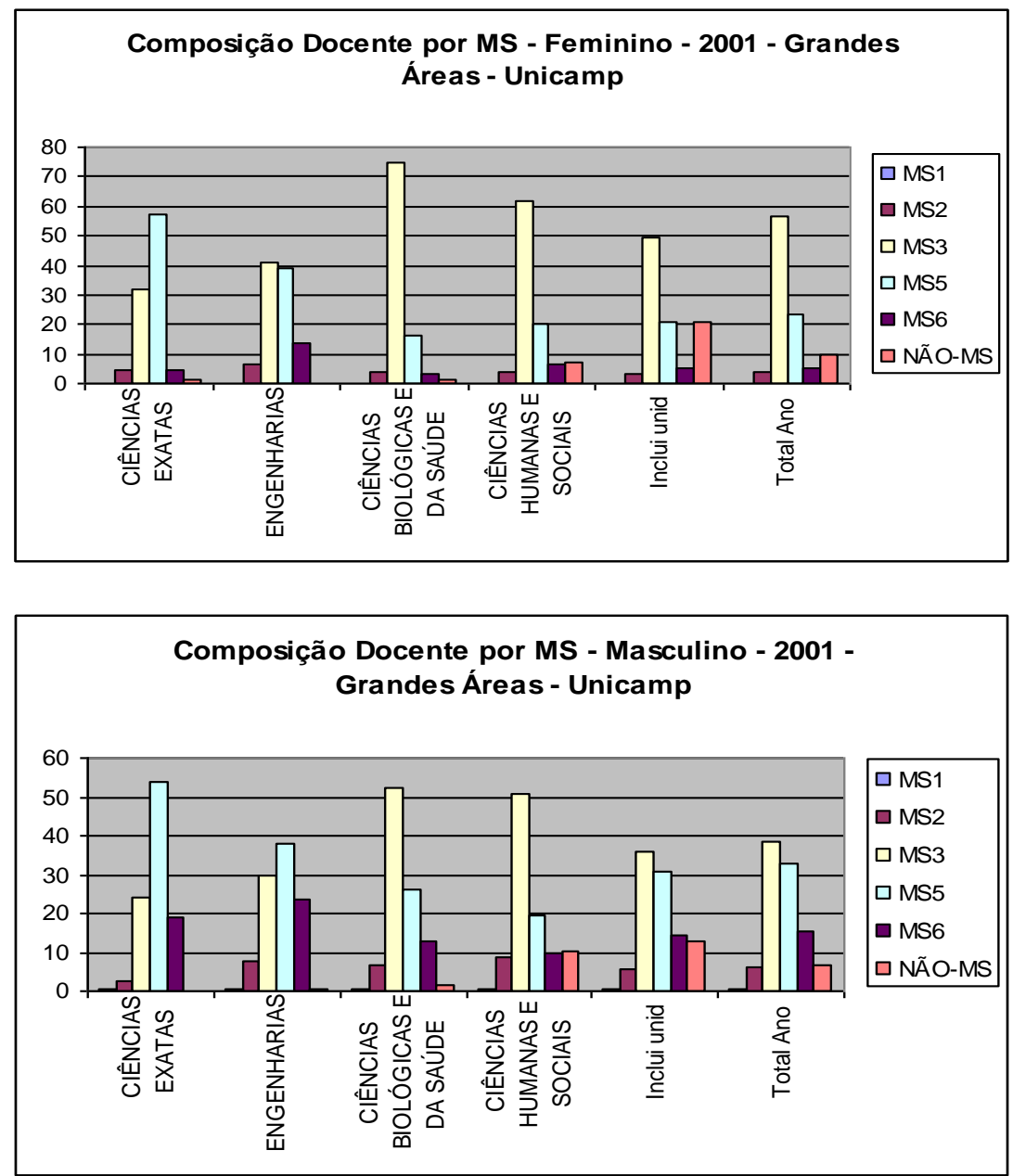

Os gráficos permitem ver:

1. A composição, diferenciada por sexo, da formação acadêmica dos docentes, no total: no caso das mulheres, a predominância 
Presença feminina no estudo e no trabalho da ciência na Unicamp

das docentes com doutorado é muito mais pronunciada que no caso dos homens, em que os professores adjuntos quase igualam os doutores em percentual.

2. Por outro lado, parte - mas apenas parte - dessa diferença é claramente atribuível à composição dos docentes por área acadêmica, pois os MS-5 predominam nas ciências exatas tanto no caso dos homens como das mulheres, embora a diferença seja maior entre os primeiros. Já nas engenharias, há mais MS-5 que MS-3 entre os homens, mas o número de professoras adjuntas (MS-5) quase se iguala ao de doutoras (MS-3), ao contrário do que ocorre nas demais áreas. Isso significa que existe um padrão de progressão na carreira diferenciado por área, que faz com que seja mais exigível a formação em níveis mais elevados nas áreas exatas - nas engenharias, por exemplo -, e menor nas biológicas e da saúde (possivelmente por uma chamada para o mercado de trabalho mais cedo que nas demais áreas) que influi também na diferenciação por sexo da composição por nível acadêmico.

3. Dessa forma, nas ciências biológicas e da saúde, bem como nas ciências humanas e sociais, a clara predominância de doutores na composição do corpo acadêmico se manifesta tanto em relação aos professores como às colegas docentes.

4. Mas é a diferença no alcance do cume da carreira acadêmica que se manifesta de forma mais acentuada, pois os professores titulares (MS-6) correspondem, em 2001, a percentuais algumas vezes maiores que as suas colegas que conseguem atingir esse nível acadêmico. 
Elza Vasconcellos e Sandra Brisolla

\begin{tabular}{|c|c|c|c|c|c|c|c|}
\hline Sexo & & & & $\operatorname{minin}$ & 2001 & & \\
\hline Grupo & & & & cente & & & \\
\hline Sub-grupo & & & MS & & & Não-MS & Total \\
\hline Nível MS & MS1 & MS2 & MS3 & MS5 & MS6 & & \\
\hline Ciências Exatas & 0 & 4,8 & 32,1 & 57,1 & 4,8 & 1,2 & 84 \\
\hline Engenharias & 0 & 6,8 & 40,7 & 39,0 & 13,6 & 0,0 & 59 \\
\hline C. Biológicas e da Saúde & 0 & 3,9 & 74,6 & 16,4 & 3,5 & 1,6 & 256 \\
\hline C. Humanas e Sociais & 0 & 4,2 & 61,8 & 19,9 & 6,8 & 7,3 & 191 \\
\hline $\begin{array}{l}\text { Sub-total Unidades } \\
\text { acadêmicas }\end{array}$ & $\mathbf{0}$ & 4,2 & 61,4 & 25,4 & 5,8 & 3,3 & 1198 \\
\hline $\begin{array}{l}\text { Unidades não } \\
\text { acadêmicas }\end{array}$ & 0,1 & 3,6 & 49,7 & 21,0 & 4,9 & 20,7 & 758 \\
\hline Total ano2001 & 0,1 & 3,9 & 56,9 & 23,7 & 5,5 & 10,0 & 1956 \\
\hline
\end{tabular}

\begin{tabular}{|c|c|c|c|c|c|c|c|}
\hline \multirow{4}{*}{\begin{tabular}{|l|} 
Sexo \\
Grupo \\
Sub-grupo \\
Nível MS \\
\end{tabular}} & \multicolumn{7}{|c|}{ Masculino 2001} \\
\hline & \multicolumn{6}{|c|}{ Docente } & Total \\
\hline & \multicolumn{5}{|c|}{ MS } & \multirow[t]{2}{*}{ Não-MS } & \\
\hline & MS1 & MS2 & MS3 & MS5 & MS6 & & \\
\hline Ciências Exatas & 0,4 & 2,6 & 24,0 & 53,9 & 19,2 & 0,0 & 271 \\
\hline Engenharias & 0,7 & 7,5 & 29,5 & 38,1 & 23,8 & 0,4 & 281 \\
\hline C. Biológicas e da Saúde & 0,3 & 6,8 & 52,4 & 26,2 & 12,7 & 1,6 & 370 \\
\hline C. Humanas e Sociais & 0,4 & 8,9 & 51,0 & 19,7 & 9,7 & 10,4 & 259 \\
\hline $\begin{array}{l}\text { Sub-total Unidades } \\
\text { acadêmicas }\end{array}$ & 0,4 & 6,5 & 40,3 & 33,7 & 16,2 & 2,9 & 2366 \\
\hline $\begin{array}{l}\text { Unidades não } \\
\text { acadêmicas }\end{array}$ & 0,4 & 5,8 & 35,9 & 30,6 & 14,3 & 13,0 & 1358 \\
\hline Total ano2001 & 0,4 & 6,3 & 38,7 & 32,6 & 15,5 & 6,6 & 3724 \\
\hline
\end{tabular}

Nas ciências exatas, em 2001, os titulares docentes são quatro vezes mais representativos no conjunto dos professores que suas colegas (4,8\% de mulheres e $19,2 \%$ de homens).

Nas engenharias, esse percentual é quase o dobro para os homens do que para as mulheres.

Nas ciências biológicas e da saúde, onde a presença feminina tem maior expressão que nas anteriores, as docentes MS6 representam apenas $3,5 \%$ do total, enquanto os titulares docentes são $12,7 \%$ do total, quase quatro vezes o percentual feminino. $\mathrm{Na}$ área médica tradicionalmente é menor a titulação docente, pois há parcela maior de docentes contratados por 
Presença feminina no estudo e no trabalho da ciência na Unicamp

tempo completo e parcial, devido à dedicação de parte do tempo de trabalho aos consultórios médicos particulares.

Nas ciências humanas e sociais é onde a diferença é menor: não chega a ser $50 \%$ maior o percentual de homens titulares sobre o total docente da área quando comparado com a relação entre as mulheres titulares e o total das docentes. Mas deve-se destacar que, no caso dos homens, esse é o menor percentual de titulares por área da Unicamp, sugerindo que parte dos docentes tenha outras atividades fora da academia que desestimule sua maior titulação.

\section{Situação em 2006}

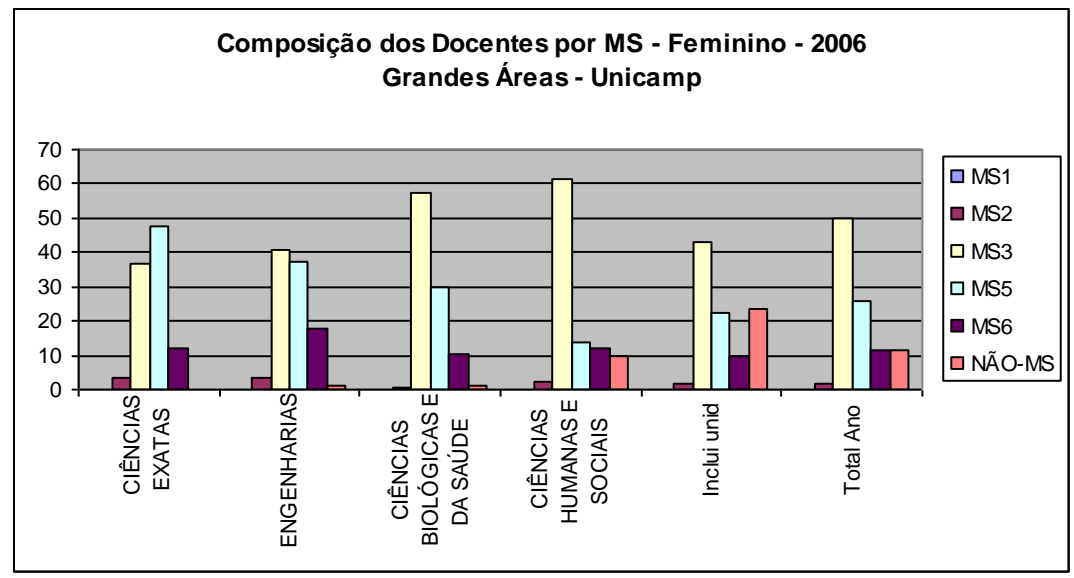




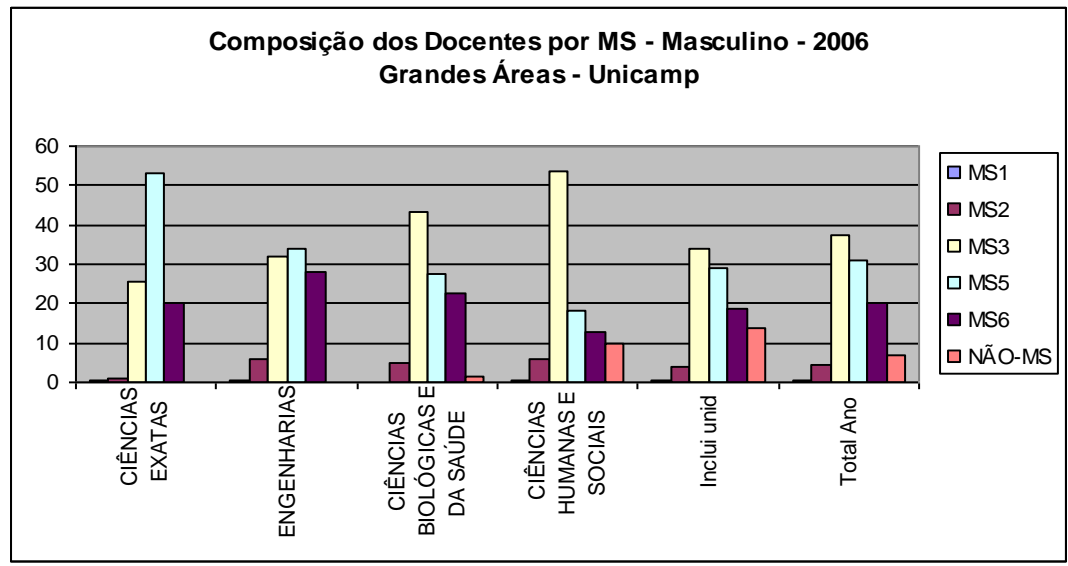

Pode-se constatar um avanço significativo tanto na composição docente em geral, na Unicamp, para homens $e$ mulheres, ainda que se mantenha a diferença entre os sexos, que, contudo, aparece atenuada.

O percentual de docentes mulheres de nível MS- 5 era menos da metade do percentual de MS-3 no conjunto da Universidade em 2001; em 2006, o gráfico mostra que esse percentual passa da metade daquele, além dos percentuais relativos aos MS-6 terem crescido bastante no período, mais para as mulheres do que para os homens, mas também no caso destes últimos.

\begin{tabular}{|c|c|c|c|c|c|c|c|}
\hline \multirow{4}{*}{$\begin{array}{l}\text { Sexo } \\
\text { Grupo } \\
\text { Sub-grupo } \\
\text { Nível MS } \\
\end{array}$} & \multicolumn{7}{|c|}{ Feminino 2006} \\
\hline & \multicolumn{6}{|c|}{ Docente } & Total \\
\hline & \multicolumn{5}{|c|}{ MS } & \multirow[t]{2}{*}{ Não-MS } & \\
\hline & MS1 & MS2 & MS3 & MS5 & MS6 & & \\
\hline Ciências Exatas & 0,0 & 3,6 & 36,9 & 47,6 & 11,9 & 0,0 & 84 \\
\hline Engenharias & 0,0 & 3,3 & 40,7 & 37,4 & 17,6 & 1,1 & 91 \\
\hline C. Biológicas e da Saúde & 0,0 & 0,8 & 57,6 & 29,8 & 10,6 & 1,2 & 245 \\
\hline C. Humanas e Sociais & 0,0 & 2,6 & 61,5 & 13,8 & 12,3 & 9,7 & 195 \\
\hline $\begin{array}{l}\text { Sub-total } \\
\text { Unidades acadêmicas }\end{array}$ & $\mathbf{0 , 0}$ & 2,0 & 54,1 & 27,6 & 12,4 & 3,8 & 1208 \\
\hline $\begin{array}{l}\text { Unidades não } \\
\text { acadêmicas }\end{array}$ & 0,0 & 1,7 & 42,9 & 22,3 & 9,7 & 23,3 & 780 \\
\hline Total ano 2006 & 0,0 & 1,9 & 49,7 & 25,6 & 11,4 & 11,5 & 1988 \\
\hline
\end{tabular}


Presença feminina no estudo e no trabalho da ciência na Unicamp

\begin{tabular}{|c|c|c|c|c|c|c|c|}
\hline \multirow{3}{*}{\begin{tabular}{|l|} 
Sexo \\
Grupo \\
Sub-grupo \\
\end{tabular}} & \multicolumn{7}{|c|}{ Masculino 2006} \\
\hline & \multicolumn{6}{|c|}{ Docente } & Total \\
\hline & \multicolumn{5}{|c|}{ MS } & \multirow[t]{2}{*}{ Não-MS } & \\
\hline Nível MS & MS1 & MS2 & MS3 & MS5 & MS6 & & \\
\hline Ciências Exatas & 0,4 & 1,1 & 25,5 & 52,9 & 20,1 & 0,0 & 278 \\
\hline Engenharias & 0,3 & 6,1 & 31,9 & 33,9 & 27,8 & 0,0 & 295 \\
\hline C. Biológicas e da Saúde & 0,0 & 5,0 & 43,1 & 27,5 & 22,7 & 1,7 & 357 \\
\hline C. Humanas e Sociais & 0,4 & 5,8 & 53,5 & 18,1 & 12,7 & 9,6 & 260 \\
\hline $\begin{array}{l}\text { Sub-total Unidades } \\
\text { acadêmicas }\end{array}$ & 0,2 & 4,7 & 39,3 & $\mathbf{3 1 , 7}$ & 21,3 & 2,7 & 2266 \\
\hline Unidades não acadêmicas & 0,3 & 4,0 & 34,1 & 29,2 & 18,7 & 13,7 & 1347 \\
\hline Total ano 2006 & 0,2 & 4,4 & 37,4 & 30,8 & 20,3 & 6,8 & 3613 \\
\hline
\end{tabular}

O percentual de MS-6 entre as mulheres na Unicamp em 2001 não atingia dois dígitos, salvo no caso das engenharias. Em 2006, todas as áreas têm percentual de dois dígitos, sendo que as engenharias se sobressaem com o maior percentual.

O mais interessante, no entanto, é ver a evolução da comparação entre os sexos no acesso ao cargo de titular: os percentuais de MS-6 entre os homens não chegam a duas vezes os das mulheres nas ciências exatas e engenharias. Nas ciências biológicas, o percentual de homens titulares no corpo acadêmico masculino é ligeiramente superior ao dobro do percentual de mulheres entre as docentes. Nas ciências humanas e sociais, o percentual de titulares é quase igual (12,7\% para os homens e 12,3 para as mulheres) para ambos os contingentes de docentes do sexo masculino e feminino.

Essas cifras dão origem a uma série de reflexões sobre a evolução da situação da universidade nos últimos cinco anos e são reveladores dos reflexos positivos de uma vida acadêmica mais democrática, menos centralizadora - conquistada a partir da Anistia e principalmente depois da autonomia das universidades públicas paulistas - sobre a relação entre os sexos e a possibilidade de ascensão na carreira docente.

Outros elementos respondem pelo nível em que essa maior mobilidade acadêmica é acompanhada pelo acesso a mecanismos de poder e cargos de direção dentro da universidade. De qualquer 
forma, as condições básicas para que se possa aceder a esses cargos são dadas pela titulação na universidade, pois essa é uma instituição de caráter meritocrático.

Tabela 20

Docentes em funções de direção, por sexo

\begin{tabular}{cccccc}
\hline Ano & Masc & Fem & Ano & Masc & Fem \\
\hline 1987 & 263 & 65 & 1997 & 285 & 149 \\
1988 & 268 & 73 & 1998 & 287 & 150 \\
1989 & 296 & 77 & 1999 & 295 & 145 \\
1990 & 285 & 78 & 2000 & 291 & 146 \\
1991 & 277 & 95 & 2001 & 282 & 155 \\
1992 & 278 & 95 & 2002 & 291 & 152 \\
1993 & 289 & 119 & 2003 & 283 & 162 \\
1994 & 280 & 127 & 2004 & 287 & 165 \\
1995 & 271 & 135 & 2005 & 290 & 164 \\
1996 & 274 & 140 & 2006 & 290 & 167 \\
\hline
\end{tabular}

Fonte: Diretoria Geral de Recursos Humanos (DGRH) da Unicamp

Esses números contrastam com a evolução por sexo entre os estudantes. Isso leva ao questionamento da igualdade: mais mulheres no estudo da ciência $=$ mais cientistas. Não se assegura um número suficiente de mulheres cientistas com titularidade e a autonomia requerida para coordenar e obter financiamento para pesquisas.

Por outro lado, o número de mulheres docentes em função de direção era um quinto do total em 1987 , e passa a um terço em 2006 (tabela 20). ${ }^{16}$

Ainda que o número de docentes homens em cargos de direção não diminua no período, o número de mulheres do corpo acadêmico ocupando essas funções eleva-se consideravelmente, aumentando sua participação no total (figura 18).

${ }^{16}$ Agradecemos a colaboração de Maria do Rosário Almeida Rocha, Coordenadora da Diretoria Geral de Recursos Humanos (DGRG/Unicamp) pela coleta e sistematização da informação referente aos docentes da Universidade. 
Presença feminina no estudo e no trabalho da ciência na Unicamp

Figura 18

Docentes em funções de direção por sexo na Unicamp

1987 a 2006

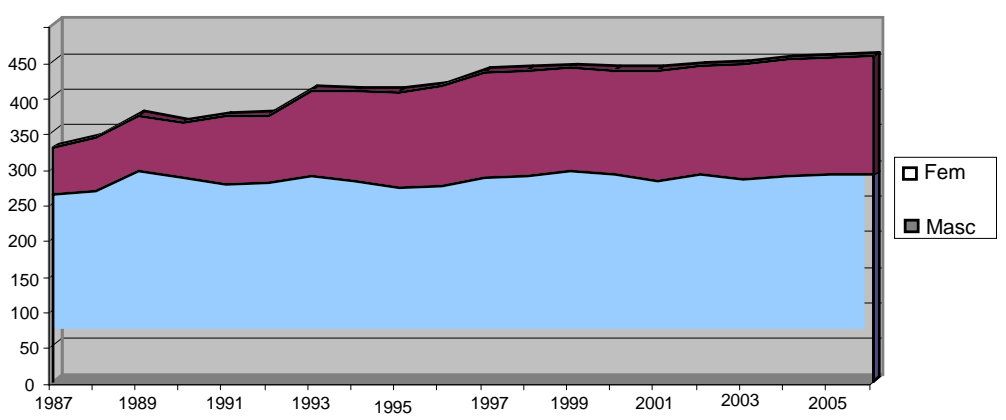

Essa progressão da participação das docentes nas funções comissionadas da universidade é uma notícia alvissareira, sem dúvida, mas deve ser vista com cuidado. Se a presença de mulheres nas chefias de departamento das unidades acadêmicas quase atinge um terço do total (40 mulheres, 85 homens, total de 125), nos altos postos diretivos, incluindo diretoria de unidades (sem incluir diretores associados), pró-reitorias e reitoria, elas não chegam a um sétimo dos cargos (4 de um total de 29; ou seja, os homens ocupam 25 desses postos), impedidas pelo teto de vidro. Quando somamos também os diretores associados, a relação passa a um quarto de mulheres nesses cargos (13 docentes do sexo feminino e 40 homens). Destaque-se que, em 2006, pela primeira vez uma professora assume o cargo de pró-reitora na Unicamp, nos seus 40 anos de vida. E a Universidade de São Paulo, a maior instituição de ensino superior no país, que faz 73 anos em 2007, também pela primeira vez tem uma mulher como reitora.

\section{Conclusões}

Como se pode observar pelos dados históricos, a situação tende naturalmente a ser suavizada, mas não de modo uniforme 
em todas as áreas ou mesmo nos diversos níveis, e nem em ritmo adequado. Assim, as medidas afirmativas, ao possibilitar a maior participação da mulher, tendem a promover em menor tempo a quase duplicação do corpo acadêmico e de pesquisa com suficiente autonomia para a gestão de projetos de pesquisa científica. Também se espera que melhorem as condições para que mulheres possam assumir os postos de direção das instituições voltadas para a ciência. Esse resultado irá beneficiar essas instituições e consequentemente as instâncias dependentes do progresso científico para a superação dos constrangimentos sociais e econômicos que o país vive e que estão na raiz do pequeno espaço para um projeto de desenvolvimento social.

Mais do que isso: a maior convivência e respeito mútuo que serão logrados entre cientistas com experiências de vida diferenciadas, por pertencerem a um ou outro sexo, irá certamente enriquecer o modo de produzir ciência e torná-lo mais permeável às necessidades de ambas as partes para a construção de uma sociedade baseada na solidariedade e na integração entre vida pública e vida privada, tendendo a humanizar a esfera do trabalho, que ocupa parcela crescente de nosso tempo nesse planeta.

\section{Referências bibliográficas}

BAKER, Elizabeth Faulkner. Technology and Women's Work. $2^{\mathrm{a}}$ ed. Nova York e Londres, Columbia University Press, 1966.

BARRET, Michele. Woman's Oppression Today - Problems in Marxist Feminist Analysis. Londres, Verso Editions and NLB, 1980.

BRISOLLA, Sandra Negraes. O Trabalho da Mulher, Ainda Discriminado. Jornal O Correio Popular, Campinas-SP, 03/05/1992.

. Participação da Mulher na Constituição do Mercado de Trabalho Urbano: estudo de Caso em Dois Municípios do Estado de São Paulo. X Encontro Anual da ANPOCS, Campos de Jordão-SP, 1986. 
Presença feminina no estudo e no trabalho da ciência na Unicamp

Formas de Inserção da Mulher no Mercado de Trabalho - O caso do Brasil. Tese de doutoramento, Departamento de Economia e Planejamento Econômico, Instituto de Filosofia e Ciências Humanas, Universidade Estadual de Campinas, 1983.

A Crise e o Comportamento Sexuado do Mercado de Trabalho. Anais da 35ª Reunião da SBPC, São Paulo, 1983.

. O Emprego não é Assexuado. Comunicação Coordenada. Anais da 34ª Reunião Anual da SBPC, São Paulo, 1982.

CARDOSO, Irede. O mito de Sísifo. Jornal Folha de São Paulo, Folhetim, 13/12/1981.

DACH, J. Norberto W. e MAIA, Rafael Pimenta. Subsídios quantitativos para repensar as políticas de acesso à Universidade, Caderno $n^{\circ} 74$, Núcleo de Estudos de Políticas Públicas (NEPP/Unicamp), jan. 2006.

DAVIDSON, Marilyn J. e COOPER, Cary L. Shattering the Glass Ceiling: The Woman Manager. London, Paul Chapman, 1992.

DeDECCA, C. S. Tempo, Trabalho e Gênero. In CostA, A. A.; OliveIRA, E. M.; LIMA, M .E. B. \& SOARES, V. Reconfiguração das Relações de Gênero e Trabalho. São Paulo, CUT, 2005.

ENGELS, Frederick. A origem da família, da propriedade privada e do Estado. São Paulo, Civilização Brasileira, 1979.

Fausto-Sterling, Anne. Dualismos em duelo. Cadernos Pagu (17/18), Campinas-SP, Núcleo de Estudos de Gênero - Pagu/Unicamp, 2001/02.

GITAHY, Leda; HIRATA, Helena; LOBO GARCIA, Elizabeth e MoYSÉs, Rosa Lúcia. Trabalho assalariado, Sindicalização e Reivindicações das Operárias (1970/1980). $1^{\circ}$ Congresso da Associação de Sociólogos do Estado de São Paulo -ASESP, São Paulo, 1981.

GUILBERT, Madeleine. Les fonctions des femmes dans l'industrie. França, The Hague, Mouton, 1966.

HIRATA, Helena. Vie Réproductive et Production: Famille et Entreprise au Japon. X Congresso Mundial de Sociologia, grupo ad-hoc Articulation $\mathrm{du}$ système productif et structures familiales: méthodologie des approches comparatives hommes-femmes, Cidade do México, DF, 1982. 
Elza Vasconcellos e Sandra Brisolla

KeRgoat, Daniele. Procès de Travail et Mobilisation Ouvrière: Procès de Travail, Sexe et Classe Sociale. Conferencia sobre la Internacionalización del Capital y el Proceso de Trabajo, México, DF, Universidade Nacional Autônoma do México, 1980.

LETA, Jacqueline. As mulheres na ciência brasileira: crescimento, contrastes e um perfil de sucesso. São Paulo, Instituto de Estudos Avançados da Universidade de São Paulo, 2004.

MADEIRA, Felícia R. \& BRUSCHINI, Maria Cristina A. A família, estrutura social $e$ as formas de participação na produção social. $1^{\circ}$ Congresso da ASESP, USP, São Paulo, 1981 [mimeo].

MARUANI, Margaret \& HIRATA, Helena. (org.) As novas fronteiras da desigualdade - homens e mulheres no mercado de trabalho, São Paulo, Editora Senac, 2003.

MorRISON, Ann M.; WhITE, Randall P.; VelSOR, Ellen Van, Center for Creative Leadership. Breaking the Glass Ceiling: Can Women Reach the Top of America's Largest Corporations? Reading, Mass., AddisonWesley, 1992.

SALm, Cláudio L. Escola e Trabalho. São Paulo, Livraria Brasiliense Editora S.A., 1980.

SANTOS, Lucy Woellner dos; ICHIKAWA, Elisa Yoshie \& CARGANO, Doralice de Fátima. (orgs.) Ciência, Tecnologia e Gênero: desvelando o feminino na construção do conhecimento. Londrina, IAPAR, 2006.

TABAK, Fanny. Mulheres Públicas - Participação Política \& Poder. Rio de Janeiro, Editora Letra Capital, 2002.

VelHO, Lea e LEÓN, Elena. A Construção Social da Produção Científica por Mulheres, Cadernos Pagu (10), Campinas-SP, Núcleo de Estudos de Gênero-Pagu/Unicamp, 1998. 